\title{
Convergent morphology and divergent phenology: unravelling the coexistence of mimetic Morpho butterfly species
}

\author{
Authors: Camille Le Roy ${ }^{1,2, *}$, Camille Roux ${ }^{3}$, Elisabeth Authier ${ }^{1}$, Héloïse Bastide ${ }^{4}$, Vincent \\ Debat $^{1}$ and Violaine Llaurens ${ }^{1}$.
}

\author{
Affiliations: \\ ${ }^{1}$ Institut de Systématique, Evolution, Biodiversité (ISYEB), Muséum National d'Histoire \\ Naturelle, CNRS, Sorbonne Université, EPHE, Université des Antilles, CP50, 75005 Paris, \\ France. \\ ${ }^{2}$ Université Paris Descartes, Sorbonne Paris Cité, 12 rue de l'École de Médecine, 75006 Paris, \\ France. \\ ${ }^{3}$ Université Lille, CNRS, UMR 8198 - Evo-Eco-Paleo, F-59000 Lille, France. \\ ${ }^{4}$ Laboratoire Evolution Génomes Comportement et Ecologie, CNRS, IRD, Université Paris- \\ Sud, Université Paris-Saclay, Gif-sur-Yvette, France.
}

\section{Abstract}

The emergence and persistence of closely-related species in sympatry is puzzling because the potential gene flow and the common local selective pressures may lead to either merging or competitive exclusion. Some species of Morpho butterflies occurring in sympatry display highly similar wing colour patterns. Associated with erratic flight abilities, their bright colouration may limit predator success and discourage future attacks. The evolution of similar colouration in sympatric species is thus likely under local selection by predators (i.e. escape mimicry). Such phenotypic similarity may promote interspecific territoriality and/or reproductive interference, questioning how closely-related co-mimetic species become sexually isolated and coexist in sympatry. We performed a series of field experiments using flying Morpho dummies placed in a natural habitat where wild males commonly patrol. Analysing the interactions of wild Morpho with different dummies, we show that similarity in wing colour pattern leads to interspecific territoriality and courtship among sympatric species. Using genomic data, we then showed that sympatric Morpho species are surprisingly strictly isolated despite their close relatedness and the observed heterospecific interactions. Finally, using a mark-recapture experiment, we discovered a strong temporal segregation in patrolling activity of males from two co-mimetic sister species. Such divergence in phenology may favour sympatry between closely-related species, despite behavioural interferences induced by the local convergence in colour pattern. Altogether, our findings show that temporal segregation may facilitate the co-existence of closely-related species sharing the same 
ecological niche, suggesting that phenological shifts may represent an overlooked factor of sympatric speciation. Our study therefore highlights how the evolution of multiple traits may favour species diversification in sympatry by partitioning niche in different dimensions.

Keywords: Reproductive interference; Territoriality; Mate recognition; Cryptic signalling; Escape mimicry.

\section{Introduction}

Natural communities are composed of multiple species involved in diverse ecological interactions either facilitating or impairing their co-existence. Shared ancestry induces ecological and morphological similarity of closely-related species, promoting their coexistence in similar niches (Wiens and Graham, 2005). However, such similarity also inherently limits this co-occurrence (Abrams, 1983; MacArthur and Levins, 1967) by increasing interspecific competition and/or reproductive interference (Brown and Wilson, 1956; Grant and Grant, 2006; Gröning and Hochkirch, 2008; Kyogoku, 2015). Furthermore, gene flow is more likely to happen between closely-related species during secondary contacts (Hewitt, 2000), and may impair their genomic and phenotypic divergence (Bolnick and Fitzpatrick, 2007). The genomic and ecological similarity may thus limit co-existence of closely-related species in sympatry.

Some types of genetic exchanges and ecological interactions might nevertheless facilitate such co-existence. Gene flow between closely-related species can indeed enhance local adaptation through introgression, enabling the rapid emergence of locally adaptive traits in colonizing species (Dasmahapatra et al., 2012; Huerta-Sánchez et al., 2014; Vekemans, 2010). Commonly inherited traits may locally benefit to individuals of closely-related species: when facing common predators for example, responding to alarm cues emitted by heterospecifics (Chivers et al., 2002; Dalesman and Rundle, 2010), or sharing a common warning signal with co-occurring species (Müller, 1879; Sherratt and Beatty, 2003). Such interspecific positive dependence is predicted to favour species co-existence (Aubier, 2020).

Shared signals among species may however enhance interspecific behavioural interference (Grether et al., 2017), including heterospecific courtship and male-male competition (Gröning and Hochkirch, 2008). Close relatedness between species then often results in reinforcement mechanisms promoting either divergent evolution of other mating cues (Saetre et al., 1997; Smadja and Ganem, 2008) or cryptic signalling (Dasmahapatra et al., 2012; Fordyce et al., 2002). Alternatively, shared signal among species may induce interspecific territoriality 
(Drury et al., 2020; Grether et al., 2017; Souriau et al., 2018), thereby reducing resource competition and facilitating coexistence in segregating spatial niches within the geographic areas (e.g. Souriau et al., 2018; Tobias and Seddon, 2009). This spatial segregation might be especially promoted in recently diverged species where heterospecific competition and mating are high (Drury et al., 2020; Drury et al., 2015). Phylogenetic relatedness and phenotypic resemblance are indeed strong predictors of interspecific territoriality (Losin et al., 2016). Ecological factors preventing character divergence might therefore also promote interspecific territoriality (Drury et al., 2020).

Selection promoting traits convergence is particularly strong in mimetic butterflies, therefore limiting population divergence in sympatry. Convergence in warning pattern indeed frequently involves convergence in other traits like flight height (Elias et al., 2008) or hostplant (Willmott and Mallet, 2004), because sharing a common microhabitat induces a higher similarity of predator communities encountered and therefore an enhanced protection (Gompert et al., 2011). Nevertheless, the benefits conferred by overlapping visual signals and ecological niches in mimetic species may in turn incur fitness cost through increased heterospecific rivalry, courtship and the expression of Dobzhansky-Müller incompatibilities in hybrids (Estrada and Jiggins, 2008; Mérot et al., 2015; Welch, 2004), ultimately limiting the co-existence of closely-related mimetic species in sympatry (Aubier et al., 2017). The conflicting ecological interactions between mimetic species therefore question their persistence in sympatry when they are closely-related.

Here we investigate how territoriality and cryptic signalling might favour the coexistence of closely-related mimetic species by focusing on sympatric Morpho butterfly species, displaying striking large blue iridescent wings (Debat et al., 2018). Although not chemically defended, these butterflies are very difficult to capture because of their fast, erratic flight. The contrast between their dorsal bright blue and ventral cryptic brownish wing surfaces induces a flash pattern during flapping flight, that was suggested to confuse predators, further increasing their difficulty of capture (Debat et al., 2018; Murali, 2018; Pinheiro and Campos, 2019; Young, 1971). Predators may then learn to avoid such elusive prey harbouring the conspicuous blue patterns. Some sympatric Morpho species were shown to locally converge in their blue pattern, probably because of frequency-dependent selection generated by predator behaviour, in a similar way as Müllerian mimics (Llaurens et al. 2020). The iridescent blue colouration of Morpho butterflies shared by sympatric species may thus reduce individual predation by advertising escape ability (the "escape mimicry" hypothesis, see Páez et al., 2020). Such local convergence might in turn impair species recognition and mate 
choice. This duality questions how closely-related co-mimetic species become sexually isolated and may coexist in sympatry.

\section{Results and Discussion}

We focused on a single locality where three mimetic species from the genus Morpho (M. achilles, M. helenor and M. deidamia) live in sympatry. In this field site, males from these three closely-related species display their typical patrolling behaviour along the river bed, allowing investigating species interactions in sympatry, as well as genomic exchanges among sympatric species.

\section{Closely-related Morpho species with mimetic colouration live in sympatry}

We performed a series of experiments at this field site, located in the Amazonian Peru, at the foothill of the Andes. We first estimate the local abundances of the different Morpho species at the study site using a mark-recapture experiment (see material and methods and Fig. S1). Morpho achilles was the most abundant species (mean \pm se $=264 \pm 68$ ), followed by $M$. helenor (mean \pm se $=195 \pm 49$ ). Individuals from $M$. deidamia were too rarely caught to allow estimating population size, suggesting a lower abundance at this site (Table S1). These three mimetic species thus co-occur at the study site, allowing relevant experiments on species co-existence.

\section{Heterospecific interactions lead to reproductive interference among sympatric species}

To test whether similarity in colour pattern among these sympatric Morpho species leads to heterospecific rivalry and courtship, we then investigated the response of patrolling males to butterfly dummies placed in the field. We built realistic dummies using the actual wings of captured Morpho, set up on a solar-powered fluttering device reproducing butterfly flying behaviour (Fig. 1; Movie S1; see also Fig. S2, S3). To ensure that only visual cues were triggering the interactions, the wings were washed in hexane prior mounting, ruling out any effect of pheromones (Darragh et al., 2017). We built 10 different dummies with the wings of specimens from different species and sexes, all caught in the same Peruvian site. We used both sexes of the two mimetic sister-species M. helenor and M. achilles, as well as of a third mimetic species $M$. deidamia, that all present an iridescent blue band bordered by proximal and distal black areas, and the phenotypically distinct M. menelaus, exhibiting fully blue iridescent wings (local dummies: $n=8$ ) (Fig. 2, S2). The last two dummies were built from the wings of males $M$. helenor and M. achilles captured in French Guiana (exotic dummies: 
$n=2$ ), exhibiting a narrower blue band relative to local - Peruvian - individuals (Fig. 2, S2). We tested all dummies $(n=10)$ following a randomized design: a different dummy was placed each morning at the same site and left fluttering on the river bank for 5 hours. This was replicated 4 times per dummy.

Over a two months period, we recorded 2,700 patrols of wild males and studied behavioural responses to dummies. We specifically focused on the behaviour of butterflies from the two mimetic sister species $M$. helenor and $M$. achilles, which represented the large majority of the passing males (35\% and $47 \%$ respectively Fig. S4). During these sessions, we scored two behaviours : (1) approaches, when a marked change in the trajectory of the passing butterfly towards the dummy was observed and (2) interactions, when the butterfly entered a $1 \mathrm{~m}^{3}$ zone around the dummy (Fig. 1). This procedure allowed us to test whether patrolling Morpho males (1) are more strongly attracted by the colour pattern of their conspecifics as compared to that of other species, (2) discriminate between sexes and (3) are more attracted by local colour patterns than by exotic ones.

\section{Long-range visual attraction to blue butterflies}

About half of the patrolling individuals deviated from their flight path to approach the setup (see Fig. S5, S6 and Table S2,S3 for more details). The differences in wing area and proportion of iridescent blue on the wing among the dummies had a limited effect on the percentage of approach (Fig. S7 and Table S4). The long range blue signals emitted by the different wing patterns displayed in the different species tested thus appeared similarly attractive for patrolling males of the sympatric species $M$. helenor and $M$. achilles, suggesting they may approach to anything roughly recognized as a potential mate or rival.

\section{Significant discrimination between local and exotic butterflies}

In both M. helenor and M. achilles, about $40 \%$ of the approaches resulted in an interaction, the visitor typically flying in circles around the dummy, with little evidence of discrimination between sympatric conspecifics and congeners, as well as between female and male dummies (Fig. 2). No effect of sex or identity of the dummy was detected on the duration of the interactions (Kruskal-Wallis test, dummy sex: Chi-square $=3.71, P=0.20, \mathrm{df}=1$; dummy identity: Chi-square $=14.03, P=0.12, \mathrm{df}=9$ ). However, interactions occurred in markedly lower proportions with the exotic dummies as compared to most local dummies (Fig. 2). Males Morpho do discriminate between slightly different colour patterns (i.e. large blue band in local individuals, vs. narrower blue band in exotic ones), but yet they largely engage in 
interactions with congeners bearing locally known signals, including signals sharply dissimilar from their own (e.g. fully blue wings in M. menelaus). Overall, dummies with larger wing area and greater proportion of iridescent blue colouration were more likely to trigger interaction (Fig. S7), suggesting that these characteristics are used by patrolling males to discriminate among dummies. Such a stronger response to local, known phenotypes (including heterospecifics) than to exotic ones (including conspecifics), has been suggested to reflect high interspecific territoriality, particularly in males (e.g. Tobias and Seddon, 2009). Consistent with this hypothesis, interactions were the most indiscriminate among male local dummies, as compared to female dummies (Fig. 2).

\section{Recognition of conspecific females in Morpho achilles}

While no significant differences were observed in interactions with dummies displaying male wings of $M$. achilles and $M$. helenor, patrolling $M$. achilles males clearly avoided its comimetic M. helenor female, but interacted indiscriminately with the dummies of the other sympatric species (i.e. M. deidamia and M. menelaus) (Fig. 2). Such a specific, acute visual discrimination towards its phenotypically closest sister species suggest that mate-recognition based on cryptic signals could have evolved in $M$. achilles, possibly as a result of reinforcement selecting against hybridization (Servedio and Noor, 2003). Reinforcement process may also occur through divergence in olfactory cues enabling discrimination among species (Mérot et al., 2015; Smadja and Ganem, 2008), although this remains to be investigated in Morpho.

To test whether the behaviour of M. achilles males differs when interacting with conspecific male and female dummies, we then equipped our set-up with a stereoscopic highspeed videography system, enabling to quantify the three-dimensional flight kinematics of visiting butterflies in natural conditions on a sub-set of sessions (Fig. 1). Striking behavioural differences were observed between the interactions toward males and females ( $n=14$ flights analysed for each sex): on average, wild males circled closer to the female than to the male dummy (regression of proportion of time spent $v s$. distance from dummy female: $P<0.001$; $R^{2}=0.07$, dummy male: $P=0.09 ; R=0.01$; Fig. 3 ). Besides, males approached the female dummy following a smoothly decelerating flight path, ensuring a steady speed when close to the female, whereas they showed more erratic accelerations around the male dummy (regression of acceleration on distance from dummy female: $P<0.001 ; R^{2}=0.14$, dummy male: $P=0.07 ; R^{2}=0.02$; Fig. 3 ). During these aerial interactions, $M$. achilles males adjust 
their flight behaviour according to the sex of their conspecific, relying solely on colour pattern visual cues.

High reproductive interferences and marked differences in discrimination behaviour between closely-related species

Altogether, our results thus clearly suggest that heterospecific contests frequently occur among males from sympatric Morpho species, and that heterospecific mating or mating attempts can frequently occur, leading to strong reproductive interferences in those sympatric species. Males from the species $M$. helenor were found to approach dummies significantly more than M. achilles (mean \% of approach in M. helenor $=48.3 \pm 15.7 ;$ M. achilles $=39.7 \pm$ 14.8; $P=0.01)$. They did not showed increased interactions with conspecific females as compared to $M$. achilles females (Fig. 2). Behavioural interferences between these sympatric species are thus large, with a higher indiscriminate behaviour in $M$. helenor than in $M$. achilles. These interspecific interactions would then induce high costs to both sexes: indiscriminate aerial contest performed with all passing individuals are energetically costly to males (Kemp, 2013; Takeuchi, 2017), while females are likely harassed by such indiscriminate mating attempts (Gröning and Hochkirch, 2008; Kyogoku, 2015; Kyogoku and Nishida, 2013). These costs could be higher in M. helenor where discrimination capacities were found lower than in M. achilles. Indiscriminate mate-searching behaviour in M. helenor moreover likely increases competition for females among males from sympatric species. This is expected to promote interspecific territoriality (Drury et al., 2020; Grether et al., 2017), in agreement with the frequent heterospecific contests observed between males $M$. helenor and M. achilles. These costly behaviours question the stable coexistence and the reproductive isolation of sympatric Morpho species.

\section{Limited genetic exchanges between species despite close relatedness and reproductive interference.}

We then sampled DNA from 31 butterflies caught at this site (13 M. achilles, 8 M. deidamia and $10 \mathrm{M}$. helenor), to explore the level of genomic exchanges among species. To specifically test whether the genomic patterns of polymorphism (Fig. S8, S9) and divergence (Fig. S10) reflect episodes of introgression between species, we performed RAD-sequencing and statistically evaluate alternative scenarios of speciation (Fig. S11), with and without gene flow using the demographic inferences with linked selection (DILS) approach (Fraisse et al., 2020). By comparing in a hierarchical approach eight categories of models according to their 
temporal patterns of migration between $M$. helenor, M. achilles and $M$. deidamia, this Approximate Bayesian Computation approach provides strong statistical support for an isolation of $M$. deidamia with both $M$. helenor and M. achilles (Fig. 4; posterior probability = 0.91). The best scenario among those proposed also describes a divergence between $M$. helenor and $M$. achilles with migration restricted to the first generations after the split (posterior probability $=0.82$ ). This analysis suggests that current putative hybridizations would not represent a significant source of intraspecific genetic diversity (Fig. 4; Table S5). Consistent with the phylogeny (Chazot et al., 2016), demographic inferences performed on our Peruvian populations revealed more recent time of split between the sister species $M$. achilles and $M$. helenor ( $T_{2}=1.11$ million generations) than between these two species and M. deidamia $\left(T_{1}=4.13\right.$ million generations). This strict isolation despite close relatedness and reproductive interference between $M$. achilles and $M$. helenor questions the ecological factors limiting hybridization in sympatry.

\section{Temporal segregation between sympatric sister-species}

By analysing the temporal variations in the mark-recapture experiments, we observed a striking difference in patrolling time among species (Kruskal-Wallis test: Chi-square $=179.7$, $P<0.001$, df =3), with little overlap between the sister species M. achilles and M. helenor (Fig. 5). Males M. helenor patrolled earlier than M. achilles (mean patrolling time \pm s.d. $=$ 11:14 \pm 00:45 vs. $12: 35 \pm 00: 40$, respectively). Patrolling time in M. deidamia (12:40 \pm 00:46) however fully overlaps that of $M$. achilles. Time of capture was remarkably similar among recaptures of a same individual in the species $M$. achilles (correlation between time of first $v s$. second capture: $r=0.40 ; P=0.05$ ), suggesting a regularity in patrolling time at the individual level in this species (Fig. 5). Whether such individual temporal regularity is genetically determined or reflects a plastic behaviour (Groot, 2014; Schöfl et al., 2009) remains to be investigated. The close phenotypic similarity of sympatric Morpho species, probably promoted by escape mimicry (Llaurens et al. 2020) might thus enhance reproductive interferences between then closely-related species $M$. helenor and M. achilles and may have favoured the evolution of divergent temporal niches. Reproductive and/or aggressive interference are generally expected to promote spatial or temporal habitat segregation between species because it reduces the cost of negative interspecific interactions (Grether et al., 2017; Robinson and Terborgh, 1995).

Altogether, our results suggest that a strong interspecific competition occurs among males from mimetic Morpho species in sympatry, but that this competition is likely mitigated by 
their temporal segregation. Heterospecific courtships may also be limited, if the temporal segregation observed in Morpho males is mirrored by a similar temporal partitioning of females activities. The activity of females butterflies is often challenging to estimate because of their highly cryptic behaviour (Devries et al., 2008), and was not measured in our study, as they were too rarely encountered. Synchronization of mating activity between sexes is however likely (Hirota et al., 2001; Iwasa and Obara, 1989), because any deviation of males relative to females activity would reduce the probability of intra-specific mating (Groot, 2014; Schöfl et al., 2009). In contrast, a shift in mating timing among species can act as a powerful isolation mechanism (Taylor and Friesen, 2017), and might explain how co-mimetic Morpho species can coexist in a same habitat while remaining sexually isolated.

Temporal segregation in butterfly mating activities may be a widespread process enabling the persistence of diversity-rich assemblages, as suggested by several reports of temporally structured sexual activities in other butterflies (Callaghan, 1982; Freitas et al., 1997; Kemp and Rutowski, 2001), including closely-related species (Devries et al., 2008). Our study on mimetic butterflies highlights that the co-existence of closely-related species can generate complex ecological interactions, both mutualistic (mimicry) and antagonistic (reproductive interference), that could be mitigated by shifts in temporal niches. Our study therefore highlights how the evolution of multiple traits may favour species diversification in sympatry by partitioning niche in different dimensions.

\section{Material and Methods}

\section{Study site and population}

The study was conducted between July and October 2019 in the North of Peru. We focused on populations of coexisting Morpho species present in the regional park of the Cordillera Escalera (San Martin Department) near the city of Tarapoto. Both the capture-recapture and the dummy experiment were performed at the exact same location, on the bank of the Shilcayo river $\left(06^{\circ} 27^{\prime} 14.364^{\prime \prime} \mathrm{S}, 76^{\circ} 20^{\prime} 45.852^{\prime \prime} \mathrm{W}\right)$.

\section{DNA extraction and RAD-Sequencing}

We used 31 wild males caught on this sites to perform population genomics analyses $(M$. achilles $-n=13$, M. helenor $-n=10$ and M. deidamia $-n=8$ ). DNA was then extracted from each sample using a slice of the thorax, using Qiagen kit DNeasy Blood \& Tissue. DNA quantification (using Qubit and Nanodrop methods) and DNA quality (by electrophoresis) was performed before the sequencing carried out in the MGX-Montpellier GenomiX platform 
(Montpellier, France). DNA digestion was performed using the Pst1 enzyme and paired-end RAD-sequencing has then been performed in one run as set out by Baird and Etter (2008) (2008), giving 299 billion reads, comprising R1 and R2 reads for each sequenced fragment. The sequencing has been performed on Illumina sequencers HiSeq2500 so that reads (125bp) were expected to be of high quality, without missing base ( $\mathrm{N}$ content). MGX then demultiplexed the data using the software Stacks (Catchen et al., 2013; Catchen et al., 2011), allowing assigning each read to his sample ID. Adapters have all been correctly removed from each reads.

\section{Reads quality, alignment and data set generation}

Reads quality has been performed using FastQC v0.11.9 software (http ://www.bioinformatics.babraham.ac.uk/projects/fastqc/). All reads have the same length: 119bp and 125bp for R1 and R2 paired-end reads respectively. Per base sequence quality were high for R1 paired-end sequences (>36) and for R2 paired-end sequences (>32) with a quality score per sequence around 39 for each reads (40 being the maximum). Sequence content per base was accurate for both R1 and R2 paired-end reads. GC content per was slightly higher than the theoretical distribution (calculated with the mean GC rate) for each reads. Thus, the high quality of reads allows avoiding read trimming or deletion.

One read alignment was realized using the Stacks V2.5 software (http ://catchenlab.life.illinois.edu/stacks/). Parameters have been set using r80 methods which maximize the number of SNPs or loci shared by at least $80 \%$ of the samples (Paris et al., 2017). The optimized parameters are "max distance between stacks" (inside each sample) and "number of mismatches between stacks" (between samples). Every other parameters have been kept to default values. Data sets were in the form of VCF data file (containing all the SNPs found in the alignment) and fasta data file (which contain the two alleles found for every loci for each sample). A RAD -sequencing locus is thus a sequence composed of 1 to 3 paired-end reads aligned together and delimited by restriction sites.

To run DILS-ABC inferences, Stacks fasta file has been converted in another fasta file compatible with DILS (https ://github.com/CoBiG2/RAD_Tools).

\section{Demographic inferences}

Eight categories of demographic models were compared, according to temporal patterns of introgression. This was done to answer two questions on gene flow in Morpho: 1) is there ongoing migration between $M$. helenor and M. achilles? 2) do M. helenor and/or M. achilles 
exchange alleles with $M$. deidamia? This was achieved by an $\mathrm{ABC}$ approach using a version of DILS adapted to samples of three populations/species (Fraisse et al., 2020).

A generalist model was studied (Fig. S11). This model describes an ancestral population subdivided in two populations: the ancestor of $M$. deidamia and the common ancestor of $M$. helenor/M. achilles. The latter population was further subdivided into the three species/populations currently sampled. Each split event is accompanied by a change in demographic size, the value of which is independent of the ancestral size. In addition, given clear genomic signatures for recent demographic changes with largely negative Tajima's $D$, we implemented variations for the effective sizes of the 3 modern lineages at independent times. Finally, migration can occur between each pair of species/populations. Migration affecting the $M$. helenor $M$. achilles pair can either be the result of secondary contact after a period of isolation (ongoing migration), or of ancestral migration (current isolation) as in (Roux et al., 2016).

As this model is over-parameterized, our general strategy is to investigate the above two questions by comparing variations of this generalist model. Thus, to test the gene flow between M. helenor and M. achilles, we compare two categories of models. 1) With random parameter values for all model parameters including the ongoing migration between $M$. helenor and M. achilles (gene flow resulting from a secondary contact between them); 2) as above, but with the migration between $M$. helenor and $M$. achilles set to zero after a randomly drawn number of generations following their split.

For each models, 50,000 of simulations using random combinations of parameters were performed. Parameters were drawn from uniform prior distributions. Population sizes were sampled from the uniform prior [0-1,000,000] (in diploid individuals); the older time of split was sampled from the uniform prior [0-8,000,000] (generations); ages of the subsequent demographic events were sampled in a uniform prior between 0 and the sampled time of split. Migration rates 4.N.m were sampled from the uniform prior [0-50]. Both migration rates and effective population sizes are allowed to vary throughout genomes as a result of link selection following (Charlesworth et al., 1993; Cruickshank and Hahn, 2014; Roux et al., 2014).

On each simulated data set we calculate a vector of means and standard deviations for different summary statistics: intraspecific statistics ( $\pi$ for M. helenor, $\pi$ for M. achilles, $\pi$ for M. deidamia, $\theta_{\mathrm{w}}$ for $M$. helenor, $\theta_{\mathrm{w}}$ for $M$. achilles, $\theta_{\mathrm{w}}$ for $M$. deidamia, Tajima's $D$ for $\mathrm{M}$. helenor, Tajima's $D$ for $M$. achilles, Tajima's $D$ for $M$. deidamia) and interspecific statistics (gross divergence, net divergence and $\mathrm{F}_{\mathrm{ST}}$ for all three possible pairs; ABBA-BABA $D$ ). 
Statistical comparisons between simulated and observed statistics were performed using the R package abcrf (Pudlo et al., 2014; Raynal et al., 2019).

\section{Mark-recapture experiment}

To estimate abundance and patrolling activity among Morpho species, we performed capturemark-recapture between 9 a.m. and 2 p.m. (flight activity in Morpho is drastically reduced in the afternoons at this site) during 17 sunny days. Although on few days, capture was aborted because of bad weather annihilating butterfly activity, the 17 capture sessions were mostly consecutives, as they were performed in a 22 days period. All butterflies were captured with hand-nets, identified at the species level, and numbered on their dorsal wing surface using a black marker. The exact time of each capture was annotated. Butterflies captured while inactive, such as those laying on a branch or on the ground were excluded from the analysis to focus exclusively on actively patrolling individuals. We measured patrolling time for a total of 295 occasions, including 78 recaptures (i.e. 217 individuals were captured at least once). All captured individuals were males. Individuals $M$. achilles were the most frequently captured $(n=121)$, followed by $M$. helenor $(n=95)$. Individuals $M$. deidamia were about half less captured $(n=48)$, and individual M. menelaus were the least captured $(n=34)$. Based on capture-recapture histories, we estimated individual abundance for each species using a loglinear model implemented in the R package Rcapture (Baillargeon and Rivest, 2007) (Fig. S1). Given the short duration the sampling period (22 days) relative to the longevity of adult Morpho butterflies (several months, Garcia et al., 2014), we used a closed-population model assuming no effect of births, deaths, immigration and emigration. Abundance was estimated in Morpho helenor and M. achilles only, as capture and re-capture events were too few in the other species (M. deidamia and M. menelaus) to allow estimating population size (Table. S1). Because striking differences in patrolling time were rapidly observed among Morpho species, we used time of the day as a predictor of species identity in order to distinguish between $M$. helenor and M. achilles in the below-described experiment because butterflies from these two species are morphologically too similar to be identified while flying (Fig. S12). After the 17 nearly-consecutive days of capture, one day of capture was repeated every 2 weeks during 2 months in parallel to the dummy experiment (described below), to verify that temporal activity was stable over time (Fig. S12). 


\section{Dummy butterflies experiment}

We investigated the response of patrolling males to sympatric conspecifics, congeners and of exotic conspecifics, using dummies placed on their flight path. Dummies were built with real wings dissected and washed with hexane to remove volatile compounds and cuticular hydrocarbons, ensuring to test only the visual aspect of the dummies. We mounted the wings on a solar-powered fluttering device (Butterfly Solar Héliobil R029br) that mimics a flying butterfly, thereby increasing the attractiveness of the dummy. The fluttering dummy was positioned on the river bank, and placed at the centre of a $1 \mathrm{~m}^{3}$ space delimitated with four vertical stacks (Fig. 1). Patrolling Morpho butterflies that deviated from their flight path to approach the dummy but did not enter the cubic space were categorized as approaching. Any Morpho butterfly entering the cubic space was considered as interacting with the dummy. Those passing without showing interest to the setup were categorized as passing. All patrolling individuals were identified at the species level, either visually for M. menelaus and M. deidamia, or based on time of the day for M. helenor and M. achilles (Fig. S12). By continuously filming the setup using a camera (Gopro Hero5 Black set at 120 images per second) mounted on a tripod, we also measured the duration of the interactions (i.e. the time spent in the cubic space) occurring between patrolling male and the dummy. The ten dummies were each tested during 4 sunny days from 9 a.m. to 2 p.m. (i.e. during 5 hours). This resulted in 40 days of experiment over which each dummy was left fluttering on the river bank for a combined duration of 20 hours. Dummies were randomly attributed to each day of experiment.

\section{Three-dimensional kinematics of flight interaction with the dummies}

To test if Morpho males shows different flight behaviours when interacting with male and female dummy, we filmed the flight interactions using two orthogonally positioned video cameras (Gopro Hero5 Black, recording at 120 images per second) around the dummy setup (Fig. 1). Stereoscopic video sequences obtained from the two cameras were synchronized with respect to a reference frame (here using a clapperboard). Prior to each filming session, the camera system was calibrated with the direct linear transformation (DLT) technique (Hartley and Zisserman, 2003) by digitizing the positions of a wand moved around the dummy. Wand tracking was done using DLTdv8 (Hedrick, 2008), and computation of the DLT coefficients was performed using easyWand (Theriault et al., 2014). After spatial and temporal calibration, we also used DLTdv8 to digitize the three-dimensional positions of both the visiting (real) butterfly and the dummy butterfly at each video frame by manually tracking 
the body centroid in each camera view. Butterfly positions throughout the flight trajectory were post-processed using a linear Kalman filter (Muijres et al., 2014), providing smoothed temporal dynamics of spatial position, velocity and acceleration of the body centroid. Based on these data, we investigated how spatial position, speed and acceleration of the visitor butterfly varied over the course of the interaction. We proceeded by dividing space into $10 \mathrm{~cm}$ spherical intervals around the dummy position ranging from 0 to 1.2 meters distance, and computed the proportion of time spent, the mean speed and acceleration of the interacting butterfly within each distance interval (Fig. 3). We analysed a total of 28 interactions performed by individual Morpho achilles male, including 14 with the dummy of its conspecific male and 14 with the dummy of its conspecific female. Analysed interactions lasted in average $1.44 \pm 0.87$ (mean \pm sd) seconds.

\section{Statistical analysis of behavioural experiments}

Differences in patrolling time were assessed by testing the effect of species on time of capture using Kruskal-Wallis test. To test the effect of visitor identity and dummy characteristics on the number of approaches and interactions, we performed logistic regressions. Approach was treated as a binary variable, where 0 meant "passing without approaching" and 1 meant "approaching the dummy setup". For the interactions, we only considered individuals approaching the setup, such as 0 meant "approaching without entering the cubic space" and 1 meant "entering the cubic space". This allowed getting rid of the uncertainties on whether passing individuals had actually seen the setup or not. We first tested the effect of visiting species on approach and interaction while controlling for dummy's characteristics to test for intrinsic differences in territoriality (or 'curiosity') among species. We then tested the effect of the dummy sex and identity on approach and interaction separately in Morpho helenor and M. achilles. The day of experiment was also included in the models to control for stochastic variation during the two-month study. We further tested if variation in wing area and proportion of iridescent blue among dummies affected the frequency of approach and interaction, again using logistic regression analyses (Fig. S7). Statistical significance of each variables was assessed using likelihood ratio tests comparing logistic regression models (Lewis et al., 2011). Finally, we tested the effect of dummy sex and identity on the duration of interaction using Kruskal-Wallis tests.

Based on the flight kinematic data, we investigated whether flight behaviour during the interaction differed with male vs. female dummies. We used linear regressions to test how variation in proportion of time spent, speed and acceleration varied with distance from 
dummy male $v s$. female during the flight interaction. We also tested for differences in mean flight distance from dummy between dummy sex using Wilcoxon test.

\section{Author Contributions}

C.L.R., V.L., and V.D. designed the research. C.L.R., V.L., V.D., C.R., E.A., and H.B. performed the research. C.L.R., V.L., and V.D. wrote the paper.

\section{Acknowledgments}

The authors would like to thank the Peruvian authorities, and in particular SERFOR (the Servicio Nacional Forestal y de Fauna Silvestre) for providing the necessary research permits (permit: 373-2017-SERFOR-DGGSPFFS). We thank Ronald Mori Pezo for help with the mark-recapture experiment. C.L.R. acknowledges financial support by Université de Paris and the Ecole Doctorale FIRE - Program Bettencourt. This work was also supported by a grant from Agence National de la Recherche under the LabEx ANR-10-LABX-0003-BCDiv, in the program "Investissements d'avenir" $\mathrm{n}$ ANR-11-IDEX-0004-02" to C.L.R and from the Emergence program of Paris city council to V.L.

\section{References}

Abrams, P. (1983). The theory of limiting similarity. Annual review of Ecology and Systematics 14, 359-376.

Aubier, T. G. (2020). Positive density dependence acting on mortality can help maintain species-rich communities. Elife $\mathbf{9}$, e57788.

Aubier, T. G., Elias, M., Llaurens, V. and Chazot, N. (2017). Mutualistic mimicry enhances species diversification through spatial segregation and extension of the ecological niche space. Evolution 71, 826-844.

Baillargeon, S. and Rivest, L.-P. (2007). Rcapture: loglinear models for capture-recapture in R. Journal of statistical software 19, 1-31.

Baird, N. A., Etter, P. D., Atwood, T. S., Currey, M. C., Shiver, A. L., Lewis, Z. A., Selker, E. U., Cresko, W. A. and Johnson, E. A. (2008). Rapid SNP discovery and genetic mapping using sequenced RAD markers. PLoS One 3, e3376.

Bolnick, D. I. and Fitzpatrick, B. M. (2007). Sympatric speciation: models and empirical evidence. Annu. Rev. Ecol. Evol. Syst. 38, 459-487.

Brown, W. L. and Wilson, E. O. (1956). Character displacement. Systematic zoology 5, 49-64.

Callaghan, C. J. (1982). A study of isolating mechanisms among Neotropical butterflies of the subfamily Riodininae. Journal of Research on the Lepidoptera 21, 159-176.

Catchen, J., Hohenlohe, P. A., Bassham, S., Amores, A. and Cresko, W. A. (2013). Stacks: an analysis tool set for population genomics. Molecular Ecology 22, 3124-3140.

Catchen, J. M., Amores, A., Hohenlohe, P., Cresko, W. and Postlethwait, J. H. (2011). Stacks: building and genotyping loci de novo from short-read sequences. G3: Genes, genomes, genetics 1, 171-182. 
Charlesworth, B., Morgan, M. and Charlesworth, D. (1993). The effect of deleterious mutations on neutral molecular variation. Genetics 134, 1289-1303.

Chazot, N., Panara, S., Zilbermann, N., Blandin, P., Le Poul, Y., Cornette, R., Elias, M. and Debat, V. (2016). Morpho morphometrics: Shared ancestry and selection drive the evolution of wing size and shape in Morpho butterflies. Evolution 70, 181-194.

Chivers, D., Mirza, R. and Johnston, J. (2002). Learned recognition of heterospecific alarm cues enhances survival during encounters with predators. Behaviour 139, 929-938.

Cruickshank, T. E. and Hahn, M. W. (2014). Reanalysis suggests that genomic islands of speciation are due to reduced diversity, not reduced gene flow. Molecular Ecology 23, 3133-3157.

Dalesman, S. and Rundle, S. D. (2010). Cohabitation enhances the avoidance response to heterospecific alarm cues in a freshwater snail. Animal Behaviour 79, 173-177.

Darragh, K., Vanjari, S., Mann, F., Gonzalez-Rojas, M. F., Morrison, C. R., Salazar, C., PardoDiaz, C., Merrill, R. M., McMillan, W. O. and Schulz, S. (2017). Male sex pheromone components in Heliconius butterflies released by the androconia affect female choice. PeerJ 5, e3953.

Dasmahapatra, K. K., Walters, J. R., Briscoe, A. D., Davey, J. W., Whibley, A., Nadeau, N. J., Zimin, A. V., Hughes, D. S., Ferguson, L. C. and Martin, S. H. (2012). Butterfly genome reveals promiscuous exchange of mimicry adaptations among species. In Nature, vol. 487, pp. 94.

Debat, V., Berthier, S., Blandin, P., Chazot, N., Elias, M., Gomez, D. and Llaurens, V. (2018). Why are Morpho Blue? In Biodiversity and Evolution, pp. 139-174: Elsevier.

Devries, P. J., Austin, G. T. and Martin, N. H. (2008). Diel activity and reproductive isolation in a diverse assemblage of Neotropical skippers (Lepidoptera: Hesperiidae). Biological Journal of the Linnean Society 94, 723-736.

Drury, J. P., Cowen, M. C. and Grether, G. F. (2020). Competition and hybridization drive interspecific territoriality in birds. Proceedings of the National Academy of Sciences 117, 1292312930.

Drury, J. P., Okamoto, K. W., Anderson, C. N. and Grether, G. F. (2015). Reproductive interference explains persistence of aggression between species. Proceedings of the Royal Society B: Biological Sciences 282, 20142256.

Elias, M., Gompert, Z., Jiggins, C. and Willmott, K. (2008). Mutualistic interactions drive ecological niche convergence in a diverse butterfly community. PLoS biology 6.

Estrada, C. and Jiggins, C. D. (2008). Interspecific sexual attraction because of convergence in warning colouration: is there a conflict between natural and sexual selection in mimetic species? Journal of Evolutionary Biology 21, 749-760.

Fordyce, J., Nice, C., Forister, M. and Shapiro, A. (2002). The significance of wing pattern diversity in the Lycaenidae: mate discrimination by two recently diverged species. Journal of Evolutionary Biology 15, 871-879.

Fraisse, C., Popovic, I., Romiguier, J., Loire, E., Simon, A., Galtier, N., Duret, L., Bierne, N., Vekemans, X. and Roux, C. (2020). DILS: Demographic Inferences with Linked Selection by using ABC. bioRxiv.

Freitas, A. V., Benson, W. W., Marini-Filho, O. J. and De Carvalho, R. M. (1997). Territoriality by the dawn's early light: the Neotropical owl butterfly Caligo idomenaeus(Nymphalidae: Brassolinae). Journal of Research on the Lepidoptera 34, 14-20.

Garcia, C. R., Gallusser, S., Lachaume, L. and Blandin, P. (2014). The ecology and life cycle of the Amazonian Morpho cisseis phanodemus Hewitson, 1869, with a comparative review of early stages in the genus Morpho (Lepidoptera: Nymphalidae: Morphinae). Tropical Lepidoptera Research 24, 67-80.

Gompert, Z., Willmott, K. and Elias, M. (2011). Heterogeneity in predator micro-habitat use and the maintenance of Müllerian mimetic diversity. Journal of theoretical biology 281, 39-46.

Grant, P. R. and Grant, B. R. (2006). Evolution of character displacement in Darwin's finches. Science 313, 224-226. 
Grether, G. F., Peiman, K. S., Tobias, J. A. and Robinson, B. W. (2017). Causes and consequences of behavioral interference between species. Trends in ecology \& evolution 32, 760772 .

Gröning, J. and Hochkirch, A. (2008). Reproductive interference between animal species. The Quarterly Review of Biology 83, 257-282.

Groot, A. T. (2014). Circadian rhythms of sexual activities in moths: a review. Frontiers in Ecology and Evolution 2, 43.

Hartley, R. and Zisserman, A. (2003). Multiple view geometry in computer vision: Cambridge university press.

Hedrick, T. L. (2008). Software techniques for two-and three-dimensional kinematic measurements of biological and biomimetic systems. Bioinspiration \& biomimetics 3, 034001.

Hewitt, G. (2000). The genetic legacy of the Quaternary ice ages. Nature 405, 907-913.

Hirota, T., Hamano, K. and Obara, Y. (2001). The influence of female post-emergence behavior on the time schedule of male mate-locating in Pieris rapae crucivora. Zoological Science 18, 475-482.

Huerta-Sánchez, E., Jin, X., Bianba, Z., Peter, B. M., Vinckenbosch, N., Liang, Y., Yi, X., He, M., Somel, M. and Ni, P. (2014). Altitude adaptation in Tibetans caused by introgression of Denisovan-like DNA. Nature 512, 194-197.

Iwasa, Y. and Obara, Y. (1989). A game model for the daily activity schedule of the male butterfly. Journal of insect behavior 2, 589-608.

Kemp, D. J. (2013). Contest behaviour in butterflies: fighting without weapons. In Animal Contests (I.C.W. Hardy \& M. Briffa, eds), pp. 134-146. Cambridge University Press, Cambridge.

Kemp, D. J. and Rutowski, R. L. (2001). Spatial and temporal patterns of territorial mate locating behaviour in Hypolimnas bolina (L.)(Lepidoptera: Nymphalidae). Journal of Natural History 35, 1399-1411.

Kyogoku, D. (2015). Reproductive interference: ecological and evolutionary consequences of interspecific promiscuity. Population ecology 57, 253-260.

Kyogoku, D. and Nishida, T. (2013). The mechanism of the fecundity reduction in Callosobruchus maculatus caused by Callosobruchus chinensis males. Population ecology 55, 87-93.

Lewis, F., Butler, A. and Gilbert, L. (2011). A unified approach to model selection using the likelihood ratio test. Methods in Ecology and Evolution 2, 155-162.

Losin, N., Drury, J. P., Peiman, K. S., Storch, C. and Grether, G. F. (2016). The ecological and evolutionary stability of interspecific territoriality. Ecology letters 19, 260-267.

MacArthur, R. and Levins, R. (1967). The limiting similarity, convergence, and divergence of coexisting species. The American Naturalist 101, 377-385.

Mérot, C., Frérot, B., Leppik, E. and Joron, M. (2015). Beyond magic traits: multimodal mating cues in Heliconius butterflies. Evolution 69, 2891-2904.

Muijres, F. T., Elzinga, M. J., Melis, J. M. and Dickinson, M. H. (2014). Flies evade looming targets by executing rapid visually directed banked turns. Science 344, 172-177.

Müller, F. (1879). Ituna and Thyridia: a remarkable case of mimicry in butterflies. Trans. Entomol. Soc. Lond 1879, 20-29.

Murali, G. (2018). Now you see me, now you don't: Dynamic flash coloration as an antipredator strategy in motion. Animal Behaviour 142, 207-220.

Páez, E., Valkonen, J. K., Willmott, K. R., Matos-Maraví, P., Elias, M. and Mappes, J. (2020). Hard to catch: Experimental evidence supports evasive mimicry. bioRxiv.

Paris, J. R., Stevens, J. R. and Catchen, J. M. (2017). Lost in parameter space: a road map for stacks. Methods in Ecology and Evolution 8, 1360-1373.

Pinheiro, C. E. and Campos, V. C. (2019). The responses of wild jacamars (Galbula ruficauda, Galbulidae) to aposematic, aposematic and cryptic, and cryptic butterflies in central Brazil. Ecological Entomology 44, 441-450.

Pudlo, P., Marin, J.-M., Estoup, A., Cornuet, J.-M., Gautier, M. and Robert, C. P. (2014). ABC model choice via random forests. ArXiv e-prints 1406, v2. 

random forests for Bayesian parameter inference. Bioinformatics 35, 1720-1728.

Robinson, S. K. and Terborgh, J. (1995). Interspecific aggression and habitat selection by Amazonian birds. Journal of Animal Ecology, 1-11.

Roux, C., Fraïsse, C., Castric, V., Vekemans, X., Pogson, G. and Bierne, N. (2014). Can we continue to neglect genomic variation in introgression rates when inferring the history of speciation? A case study in a M ytilus hybrid zone. Journal of Evolutionary Biology 27, 1662-1675.

Roux, C., Fraisse, C., Romiguier, J., Anciaux, Y., Galtier, N. and Bierne, N. (2016). Shedding light on the grey zone of speciation along a continuum of genomic divergence. PLoS biology 14, e2000234.

Saetre, G.-P., Moum, T., Bures, S., Kral, M., Adamjan, M. and Moreno, J. (1997). A sexually selected character displacement in flycatchers reinforces premating isolation. Nature 387, 589-592.

Schöfl, G., Heckel, D. G. and Groot, A. (2009). Time-shifted reproductive behaviours among fall armyworm (Noctuidae: Spodoptera frugiperda) host strains: evidence for differing modes of inheritance. Journal of Evolutionary Biology 22, 1447-1459.

Servedio, M. R. and Noor, M. A. (2003). The role of reinforcement in speciation: theory and data. Annual Review of Ecology, Evolution, and Systematics 34, 339-364.

Sherratt, T. N. and Beatty, C. D. (2003). The evolution of warning signals as reliable indicators of prey defense. The American Naturalist 162, 377-389.

Smadja, C. and Ganem, G. (2008). Divergence of odorant signals within and between the two European subspecies of the house mouse. Behavioral ecology 19, 223-230.

Souriau, A., Kohoutová, H., Reif, J., Vokurková, J., Petrusek, A., Reifová, R. and Petrusková, T. (2018). Can mixed singing facilitate coexistence of closely related nightingale species? Behavioral ecology 29, 925-932.

Takeuchi, T. (2017). Agonistic display or courtship behavior? A review of contests over mating opportunity in butterflies. Journal of ethology 35, 3-12.

Taylor, R. S. and Friesen, V. L. (2017). The role of allochrony in speciation. Molecular Ecology 26, 3330-3342.

Theriault, D. H., Fuller, N. W., Jackson, B. E., Bluhm, E., Evangelista, D., Wu, Z., Betke, M. and Hedrick, T. L. (2014). A protocol and calibration method for accurate multi-camera field videography. Journal of Experimental Biology, jeb. 100529.

Tobias, J. A. and Seddon, N. (2009). Signal design and perception in Hypocnemis antbirds: evidence for convergent evolution via social selection. Evolution: International Journal of Organic Evolution 63, 3168-3189.

Vekemans, X. (2010). What's good for you may be good for me: evidence for adaptive introgression of multiple traits in wild sunflower. The New Phytologist 187, 6-9.

Welch, J. J. (2004). Accumulating Dobzhansky-Muller incompatibilities: reconciling theory and data. Evolution 58, 1145-1156.

Wiens, J. J. and Graham, C. H. (2005). Niche conservatism: integrating evolution, ecology, and conservation biology. Annu. Rev. Ecol. Evol. Syst. 36, 519-539.

Willmott, K. R. and Mallet, J. (2004). Correlations between adult mimicry and larval host plants in ithomiine butterflies. Proceedings of the Royal Society of London. Series B: Biological Sciences 271, S266-S269.

Young, A. M. (1971). Wing coloration and reflectance in Morpho butterflies as related to reproductive behavior and escape from avian predators. Oecologia 7, 209-222.

\section{Figures and tables}




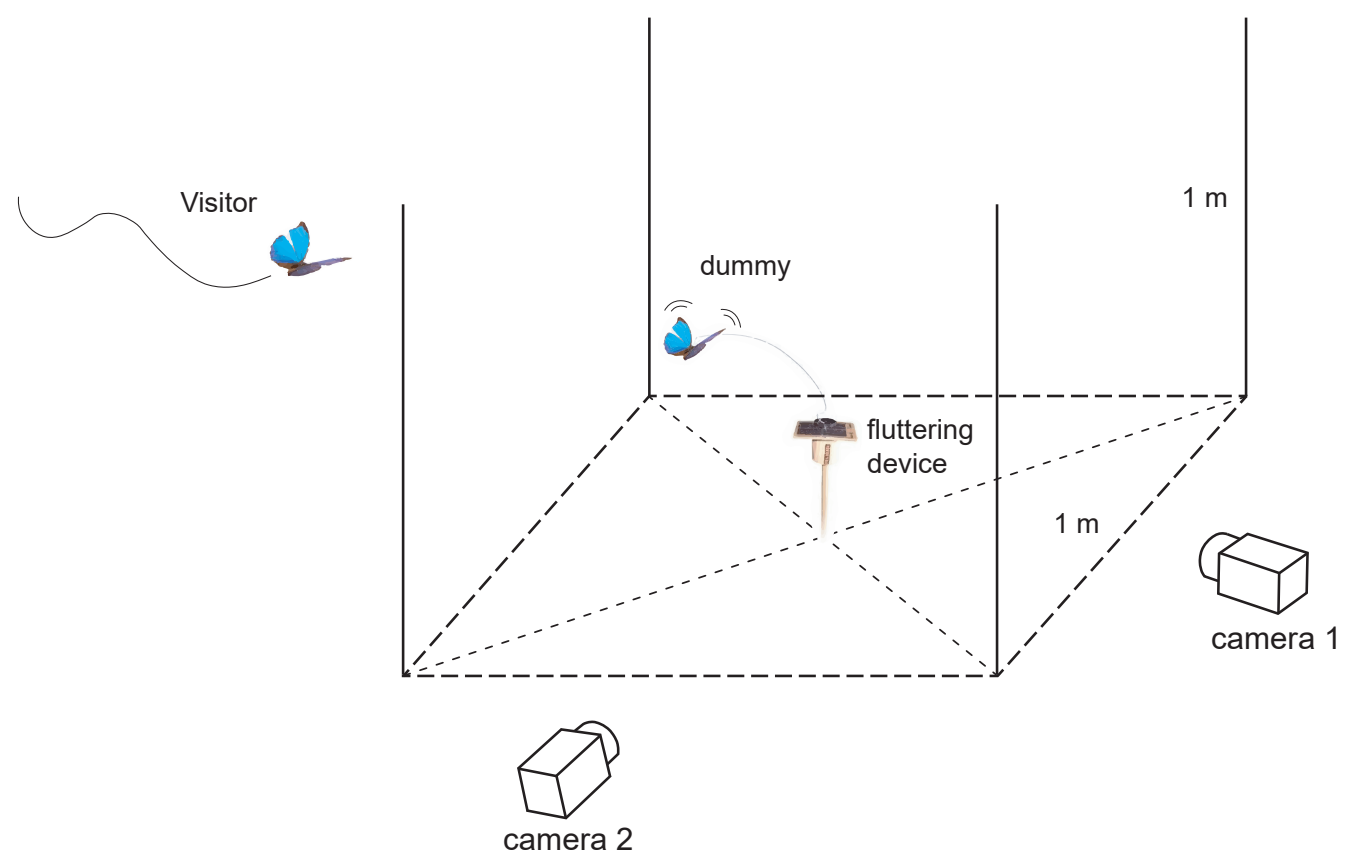

Fig. 1. Experimental set up used to study flight interaction. The dummy butterfly was placed at the centre of a cubic area materialized by four $1 \mathrm{~m} 3$-sticks, and fixed to a solar-powered fluttering device reproducing butterfly flying behaviour. Interaction between visitor and dummy butterfly (defined as a visitor entering in the cubic area) were recorded using stereoscopic high-speed videography system, allowing to quantify flight trajectory during the interaction (see Fig. 3). 
visitor M. helenor

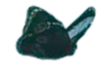

visitor M. achilles

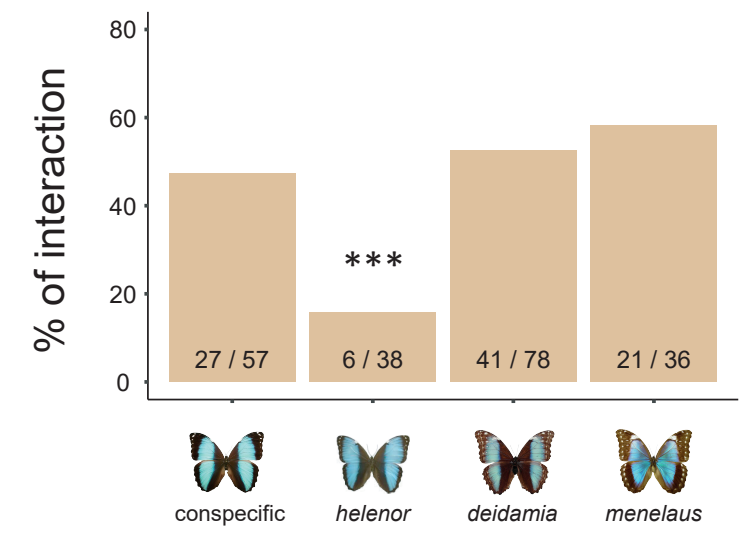

Female dummies
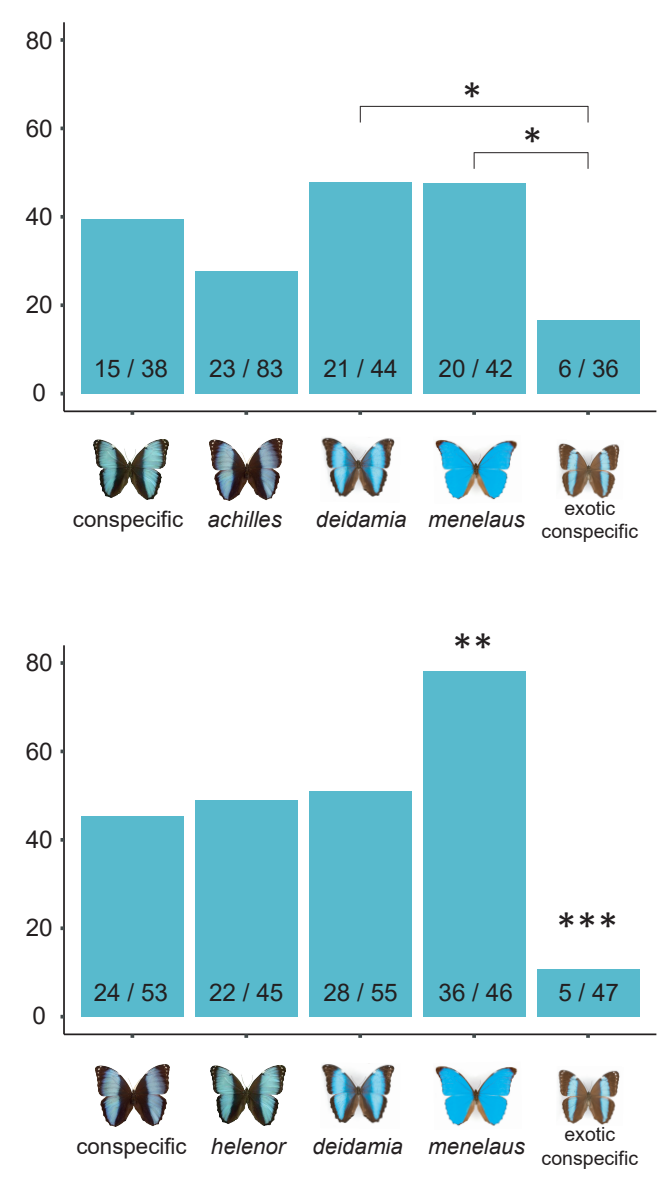

Male dummies

Fig. 2. Variation in interaction frequency with conspecific and congener dummies in two mimetic sister

Morpho species. Morpho helenor (top row) and M. achilles (bottom row) engage in interaction with sympatric conspecifics and congeners (females: left column, males: right column) in broadly similar proportion. Note that males M. achilles showed limited courtships with the female of its co-mimetic sister and that percentage of interaction was consistently lower with the exotic male conspecific in both species. Raw data « nb of interactions / $\mathrm{nb}$ of approaches » are indicated on each barplot. 
A
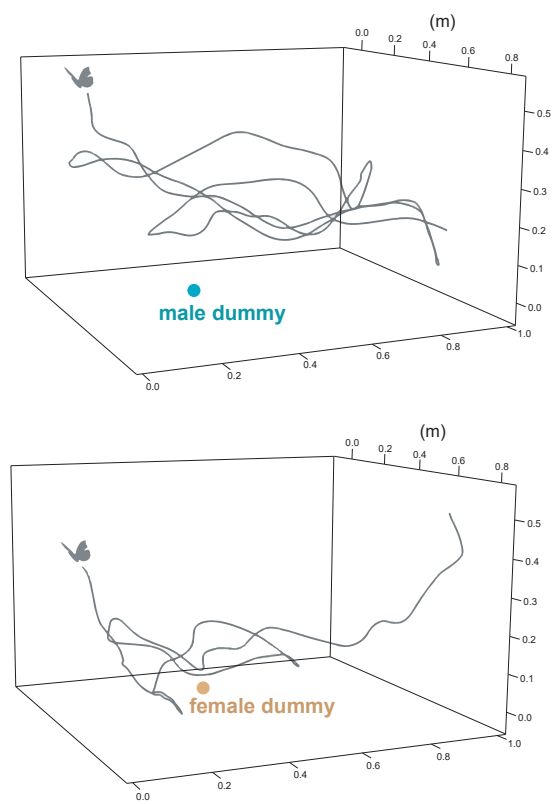

B

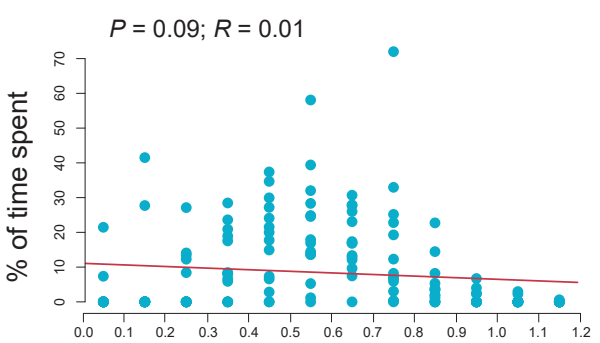

$P<0.001 ; R=0.07$

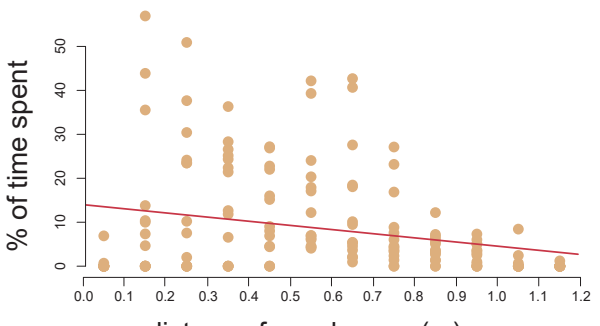

distance from dummy $(\mathrm{m})$
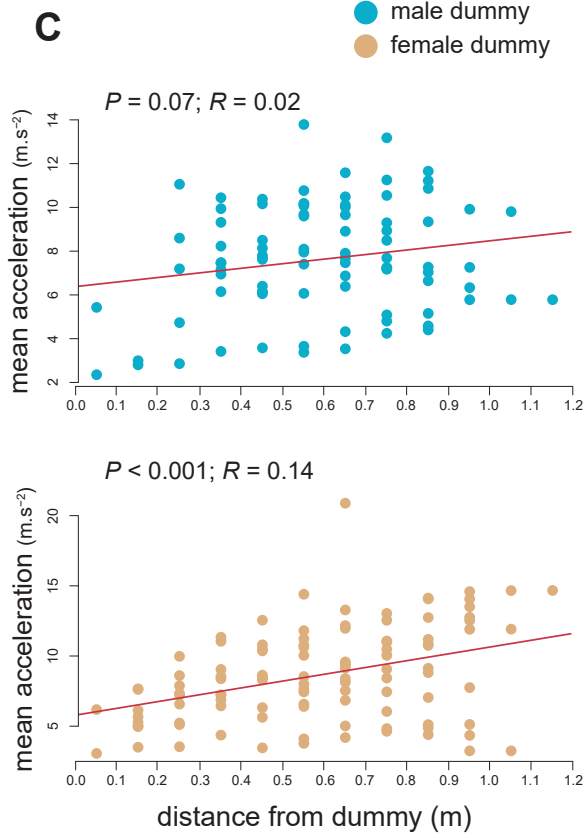

Figure 3. Three-dimensional kinematic of contest and courtship flights. (A) Example of flight path when circling around the dummy conspecific male (top) and female (bottom). (B) The proportion of time spent circling at short-distance from the dummy significantly increases for dummy female only. (C) A significantly positive relationship between acceleration and distance from dummy is observed for dummy female only. $\mathrm{N}=14$ flight interactions analysed with the dummy male and 14 with the dummy female. 


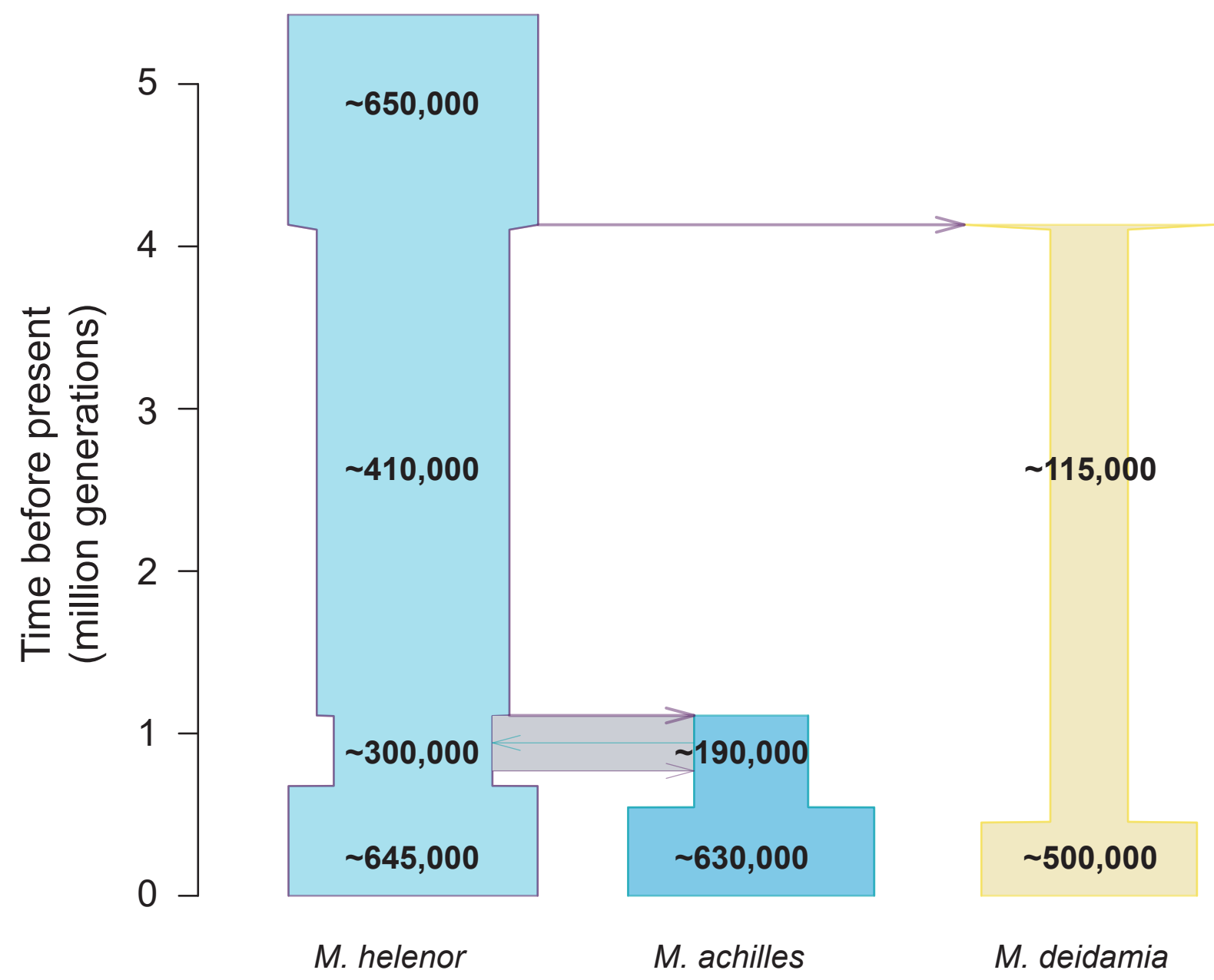

Fig. 4. Best inferred demographic scenario from RAD-sequencing data. Eight categories of scenarios were compared according to different temporal patterns of gene flow: between $M$. helenor and $M$. achilles (ancestral migration or secondary contact); with $M$. deidamia (strict isolation, migration only with M. helenor, migration only with M. achilles, migration between the 3 species). The times of demographic events (speciation, cessation of migration and changes $\mathrm{n}$ population size) are shown on the $\mathrm{Y}$-axis in millions of generations. The grey rectangle indicates the period when $M$. helenor and $M$. achilles were, according to the demographic model fitting the best the molecular dataset, genetically connected through migration events. 
A

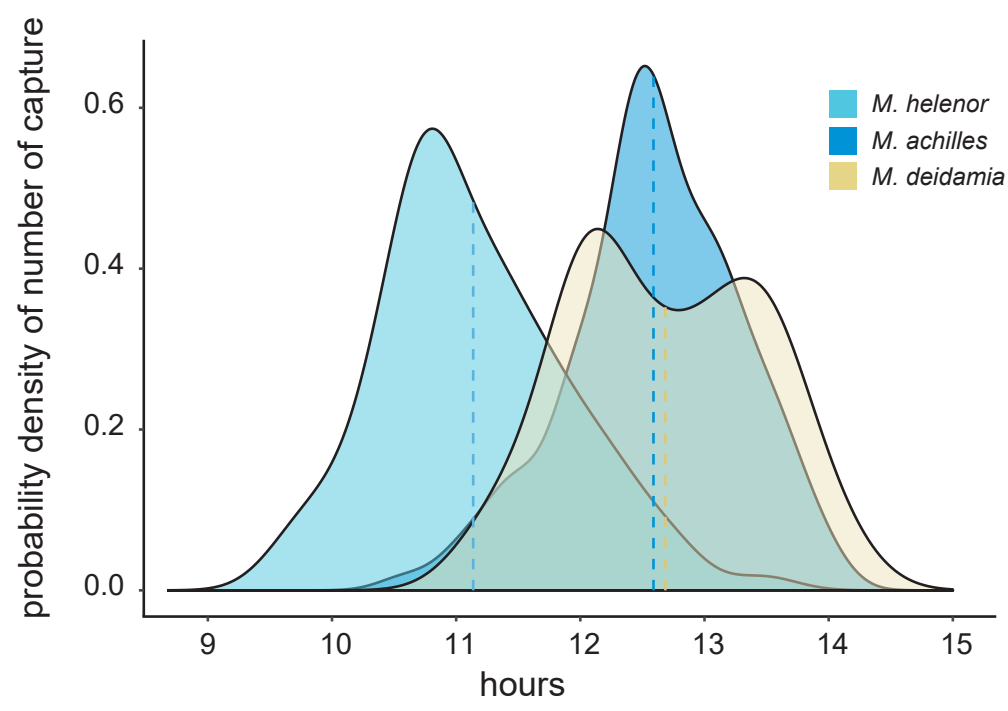

B

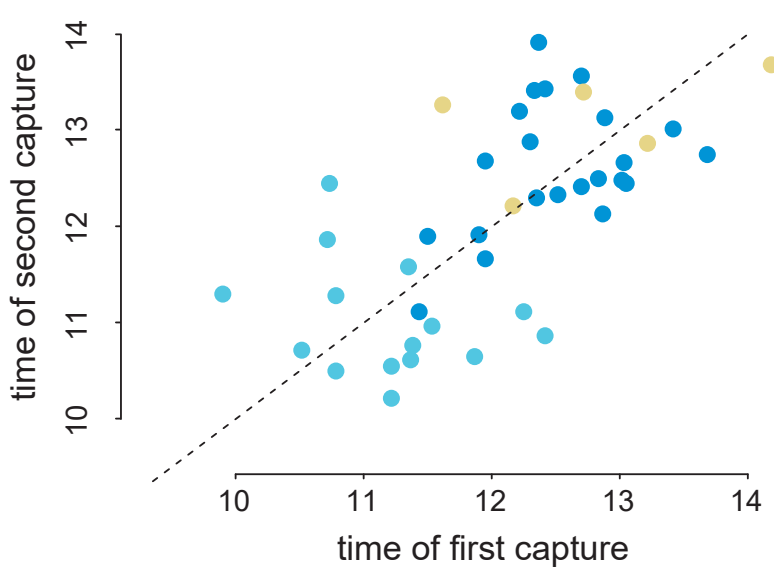

Fig. 5. Patrolling time among sympatric species and individuals. (A) Segregation of patrolling time over the day among Morpho species. Dashed vertical lines indicate the mean flight time. (B) Plot of first versus second capture time among recaptured individuals. Dashed line represents exact same time between first and second capture. 

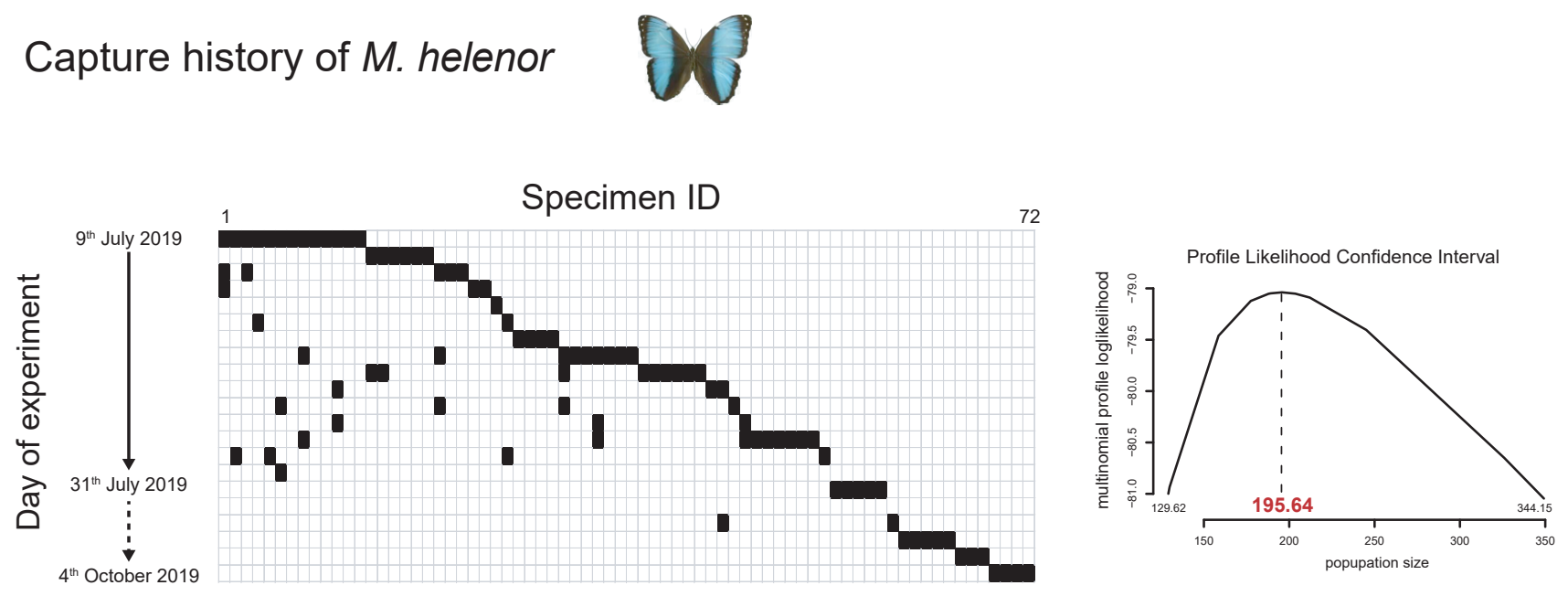

Capture history of $M$. achilles
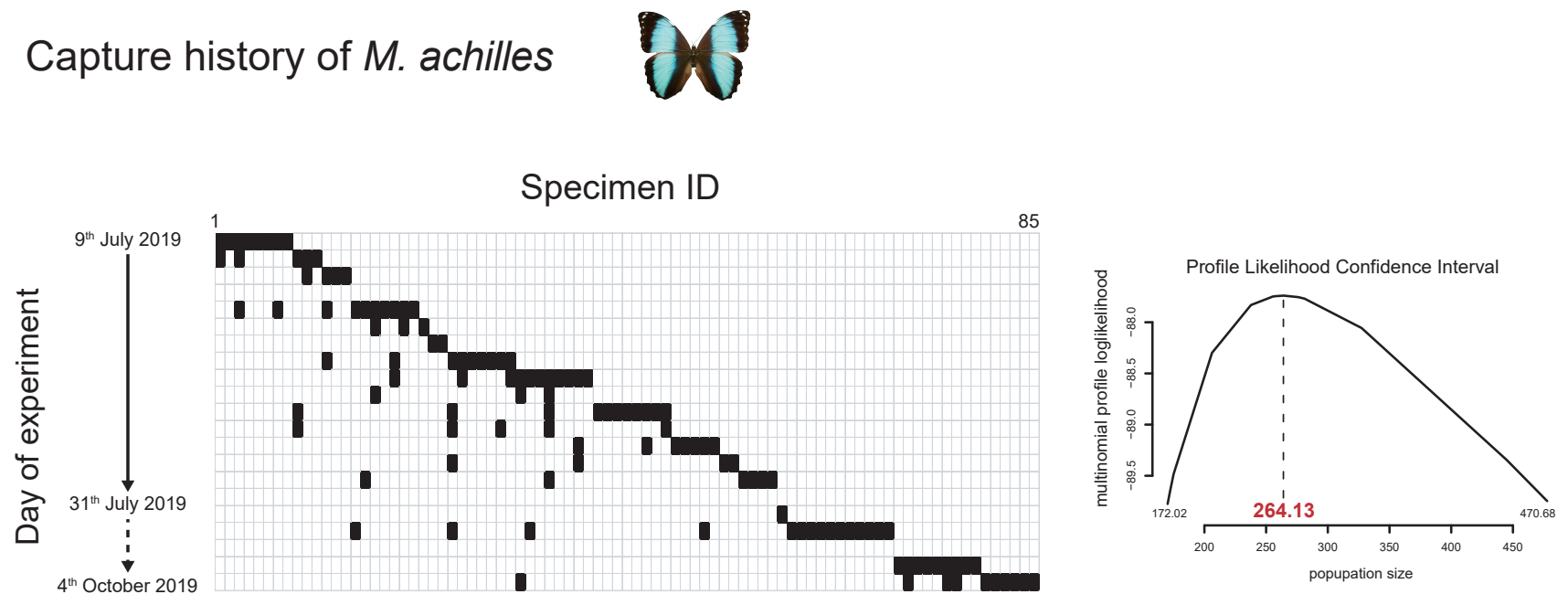

Fig. S1. Estimating population size from mark-recapture data. Capture history is shown for the two mimetic sister species M. helenor (top) and $M$. achilles (bottom). It gives the capture status on each day of experiment: caught (black boxes) or uncaught (white boxes). Days of experiment along the continuous arrow were nearly consecutive, while those along the dashed arrow were performed every 2 weeks.

Based on capture-recapture histories, we estimated individual abundance for each species using a loglinear model implemented in the R package Rcapture (Baillargeon \& Rivest 2007), assuming constant population size throughout the experiment. The likelihood confidence interval of the population sizes is shown on the right column. 
bioRxiv preprint doi: https://doi.org/10.1101/2020.1126.399931; this version posted November 27, 2020. The copyright holder for this preprint (which was not certified by peer review) is the author/funder, who has granted bioRxiv a license to display the preprint in perpetuity. It is made available under aCC-BY-NC-ND 4.0 International license.

\section{Males}
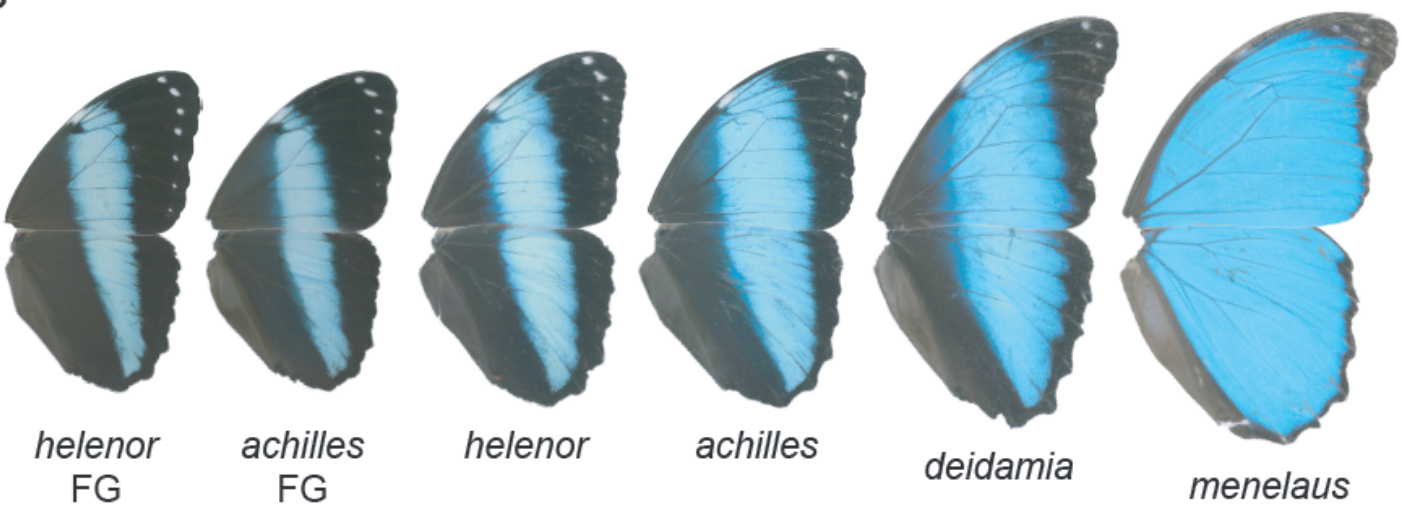

$3 \mathrm{~cm}$

\section{Females}

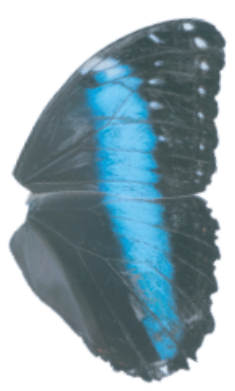

helenor

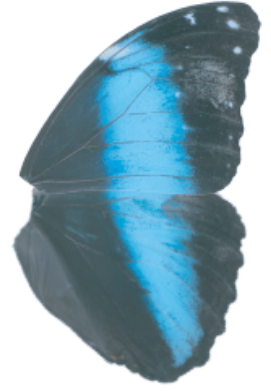

achilles

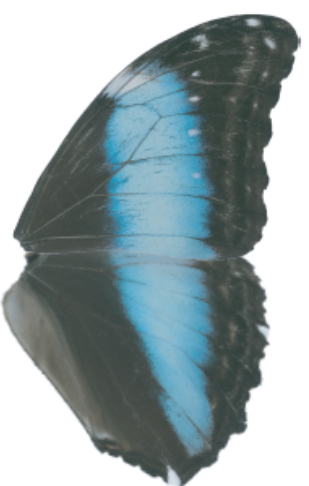

deidamia

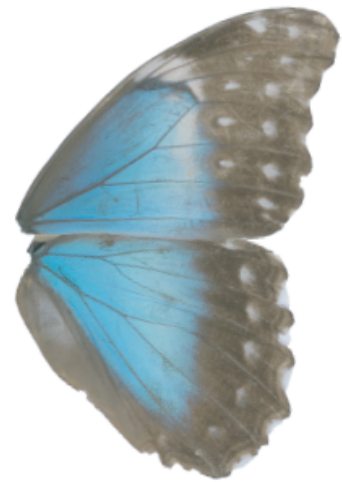

menelaus

Fig. S2. Wings of Morpho butterflies used for the dummy experiment. 'FG' indicates exotic dummies from French Guiana. All other dummies were build with wings from Peruvian individuals. Wings are shown at their relative size. 


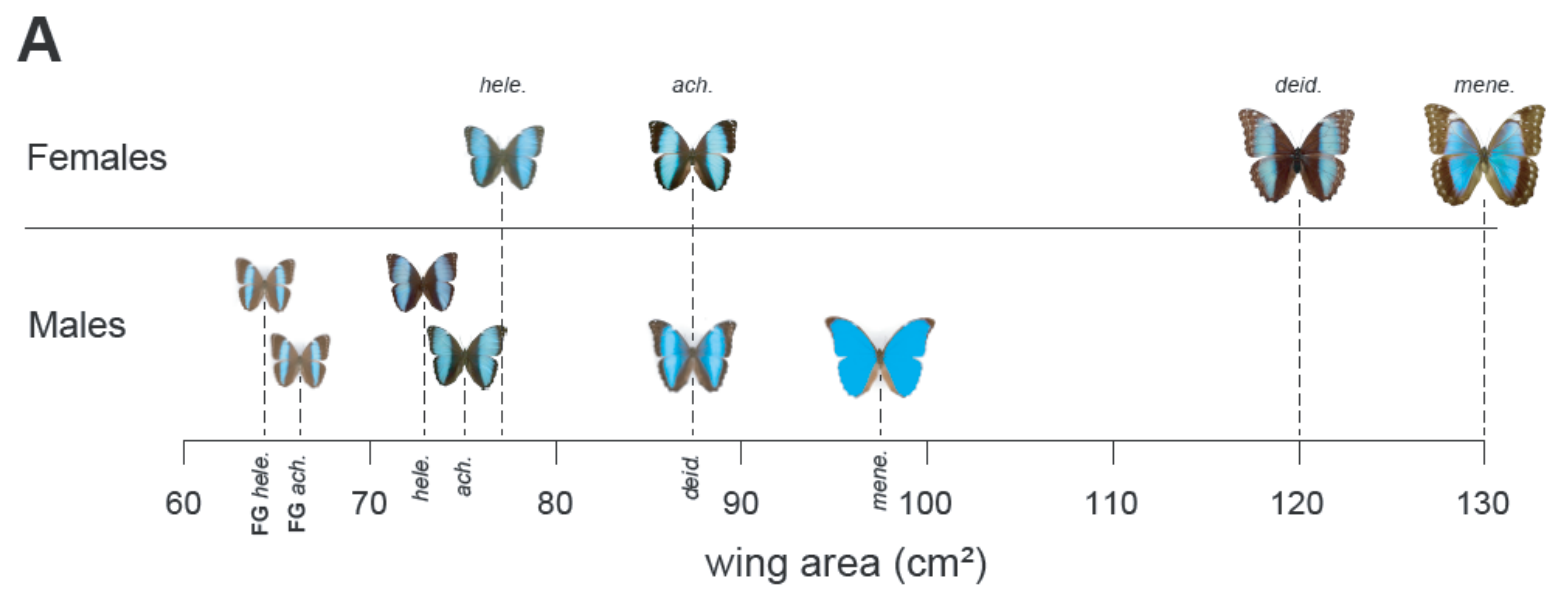

B

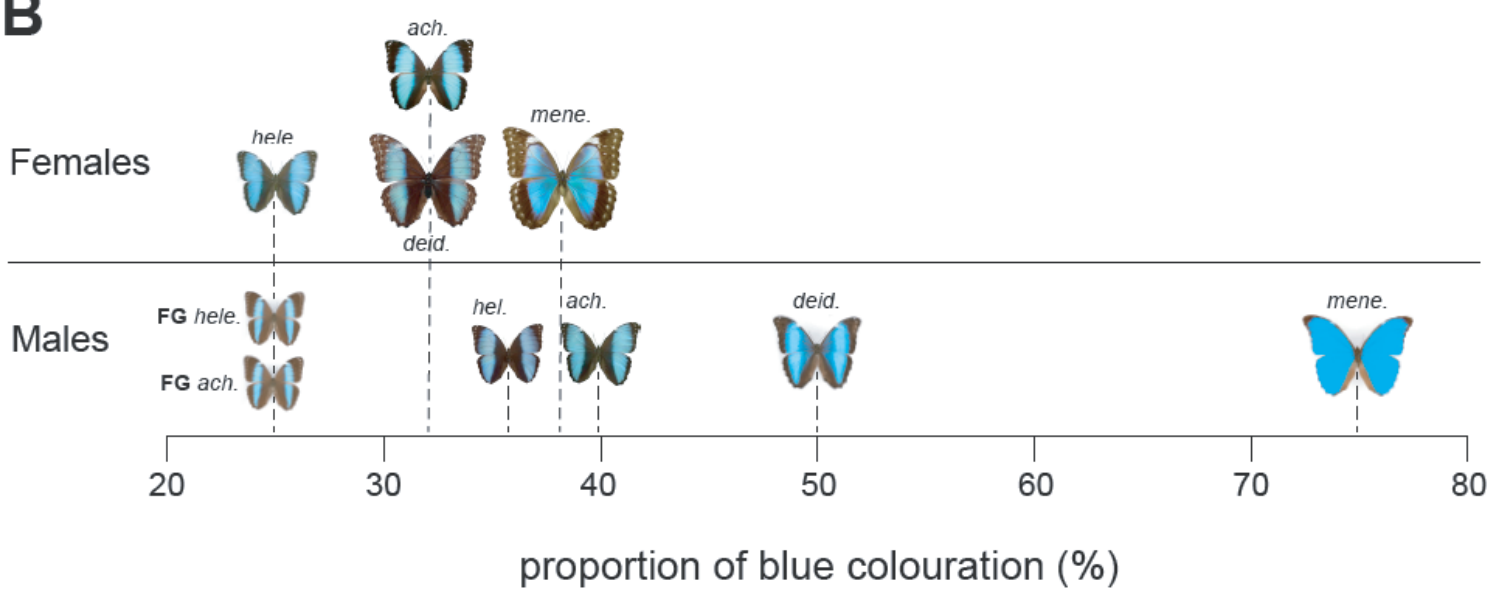

Fig. S3. (A) Variation in wing area and (B) in proportion of blue colouration among the tested dummy butterflies. 'FG' indicates exotic dummies from French Guiana. All other dummies were build with wings from Peruvian individuals. 


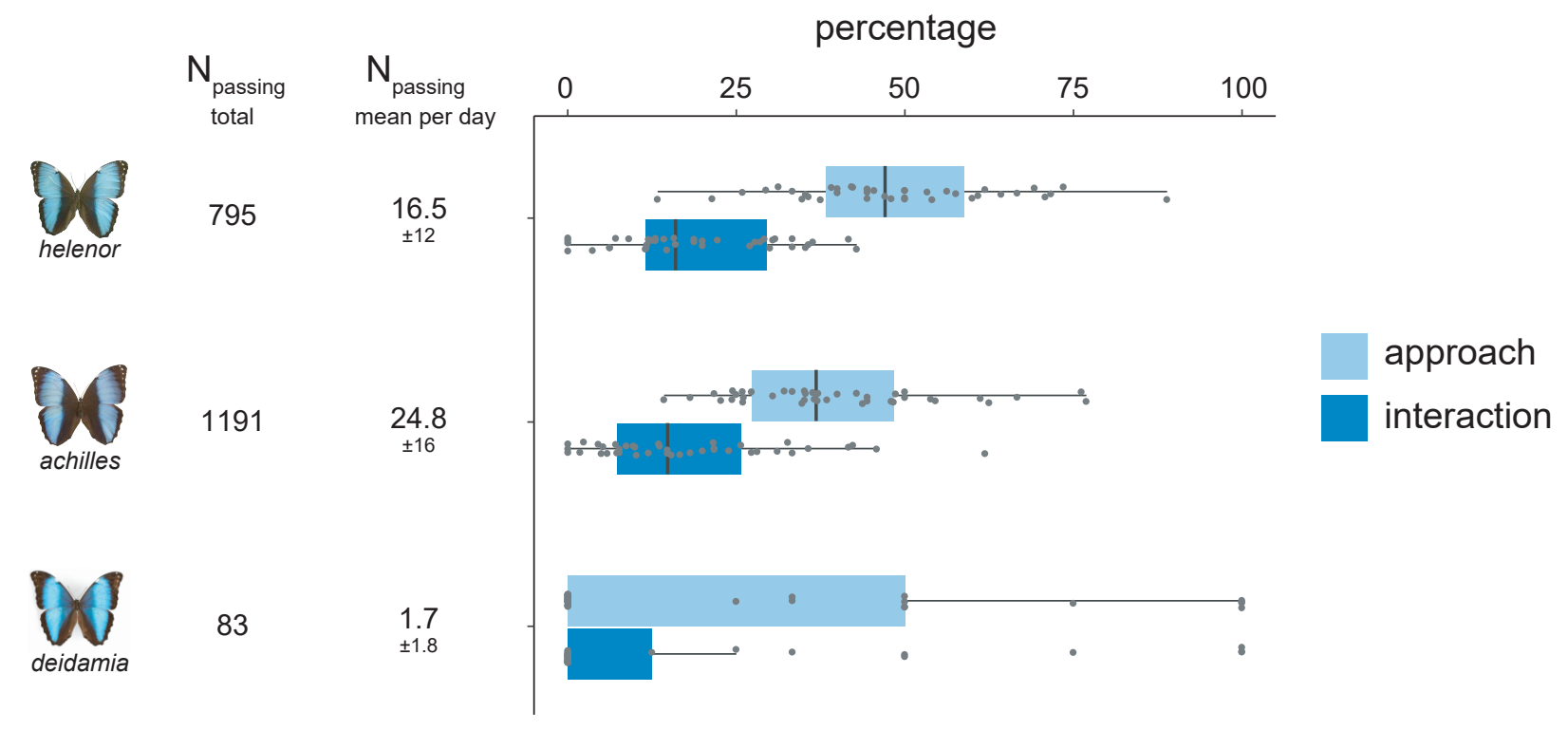

Fig. S4. Percentage of approach and interaction with the dummy butterfly (all dummy identity and sex confounded) among sympatric Morpho species. Percentage were computed over the number of passing individuals along the river. Total number of passing Morpho (in 40 day of experiment) and mean per day is indicated on the left. Each point on the boxplot represent a different day of experiment. 

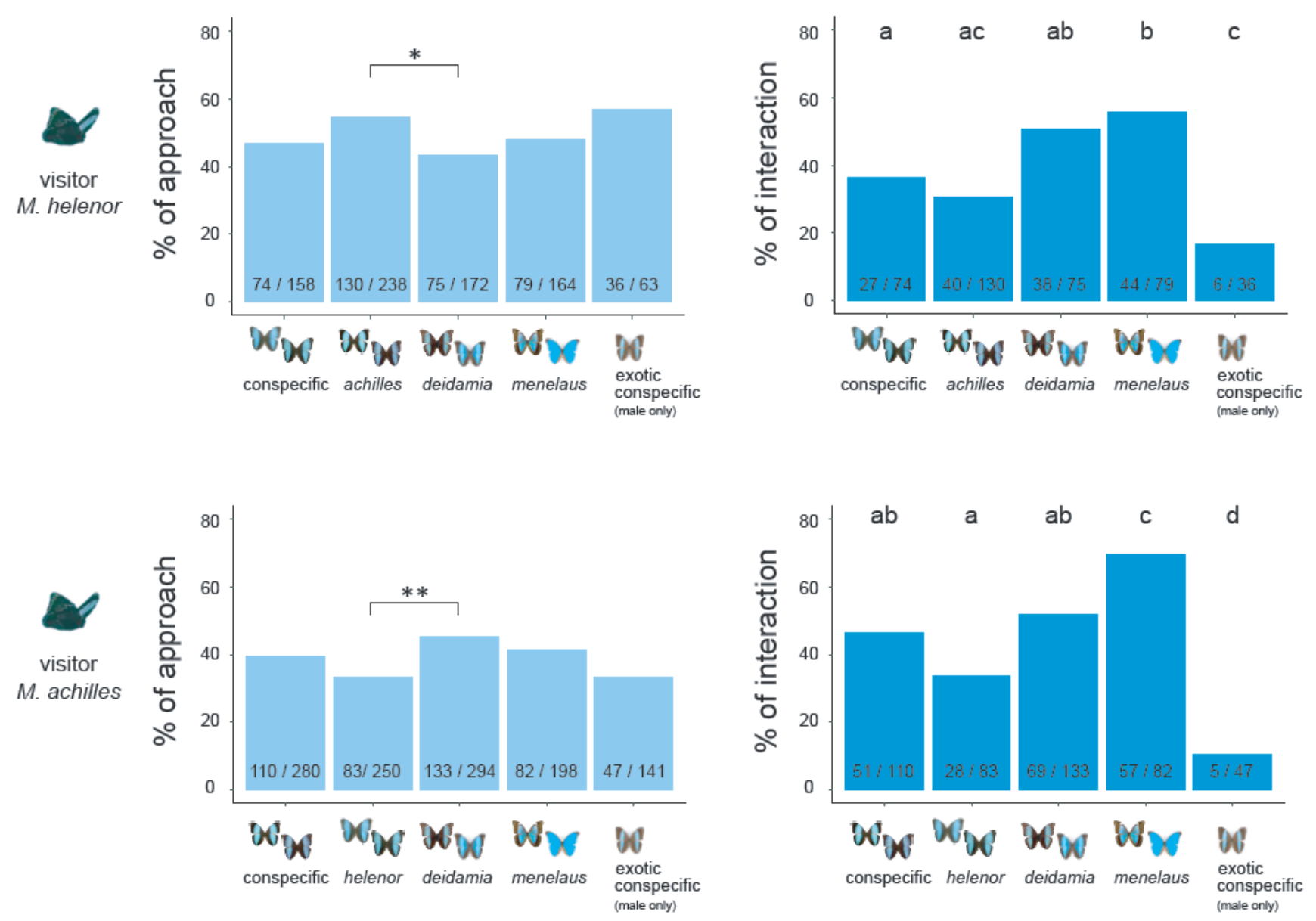

Dummies (male and female pooled)

Fig. S5. Variation in approach (left column) and interaction (right column) frequency with conspecific and congener dummies in two mimetic sister Morpho species (males and females dummies pooled). Female and male dummies are pooled together, excepted for the exotic dummies where only males were tested.

Raw data « $\mathrm{nb}$ of approaches / $\mathrm{nb}$ of passing» are indicated on barplots of the left column.

« $\mathrm{nb}$ of interaction/ $\mathrm{nb}$ of approaches» are indicated on barplot of the right column. 
bioRxiv preprint doi: https://doi.org/10.1101/2020.11.26.399931: this version posted November 27, 2020. The copyright holder for this preprint (which was not certified by peer review) is the author/funder, who has granted bioRxiv a license to display the preprint in perpetuity. It is made available under aCC-BY-NC-ND 4.0 International license.
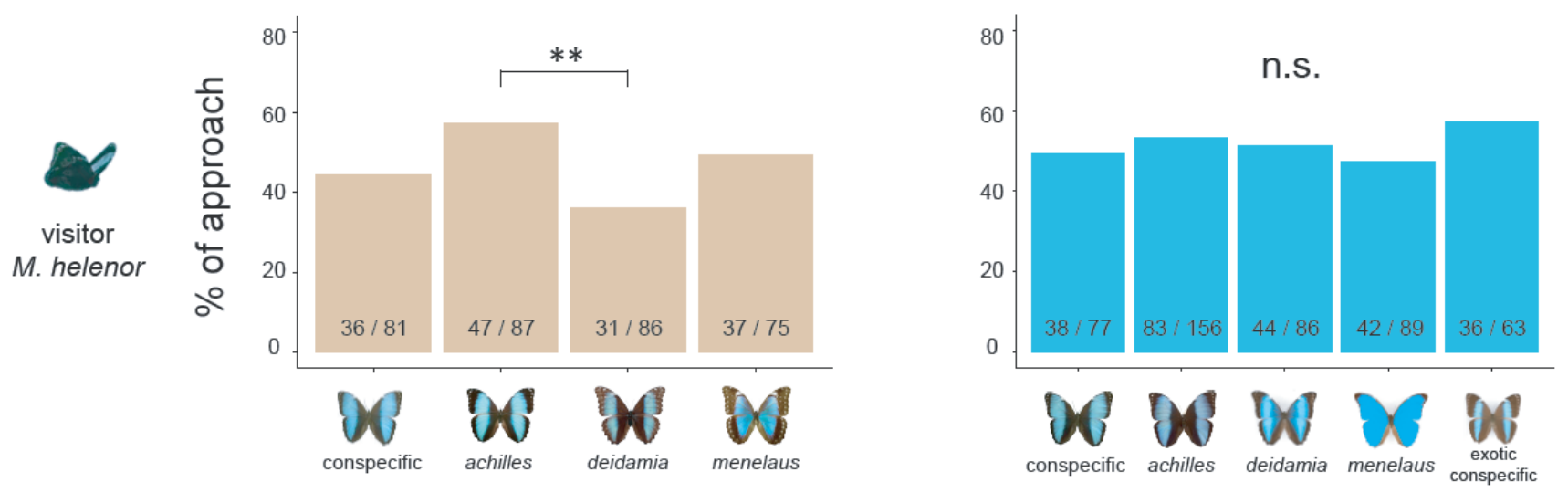

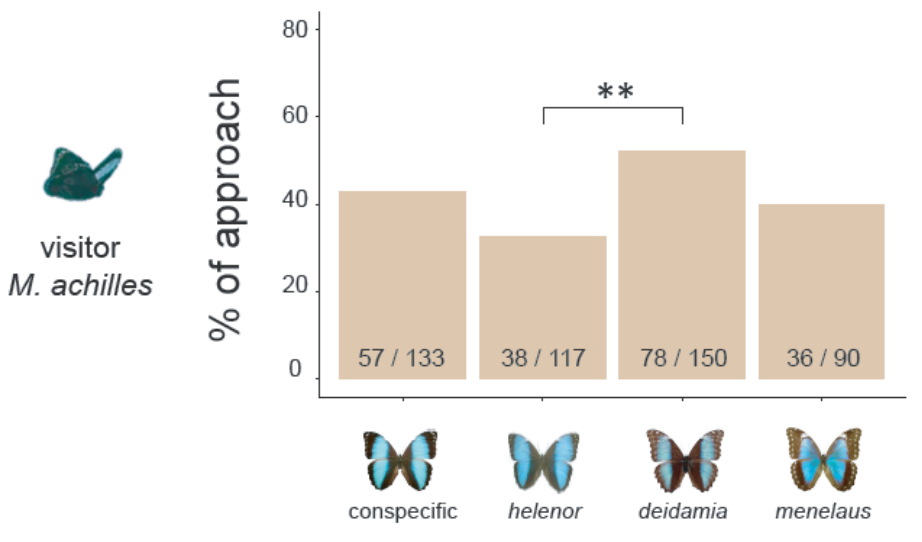

Female dummies

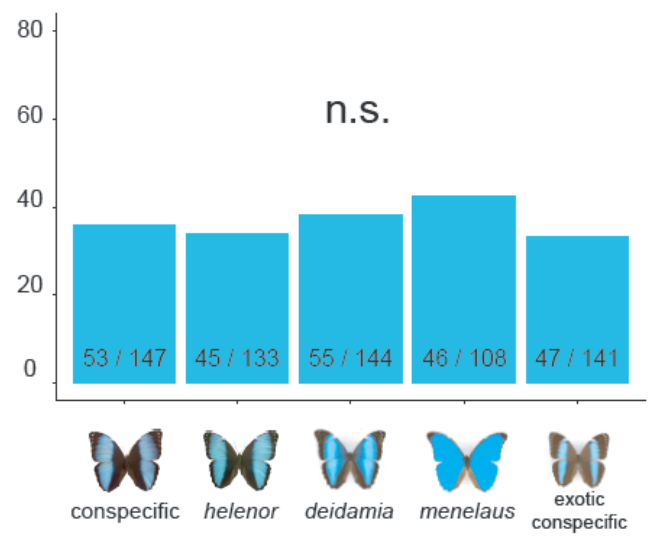

Male dummies

Fig. S6. Variation in approach frequency with conspecific and congener dummies in two mimetic sister Morpho species. Raw data « nb of approaches / nb of passing » are indicated on each barplot. 


\section{Visitor M. helenor}
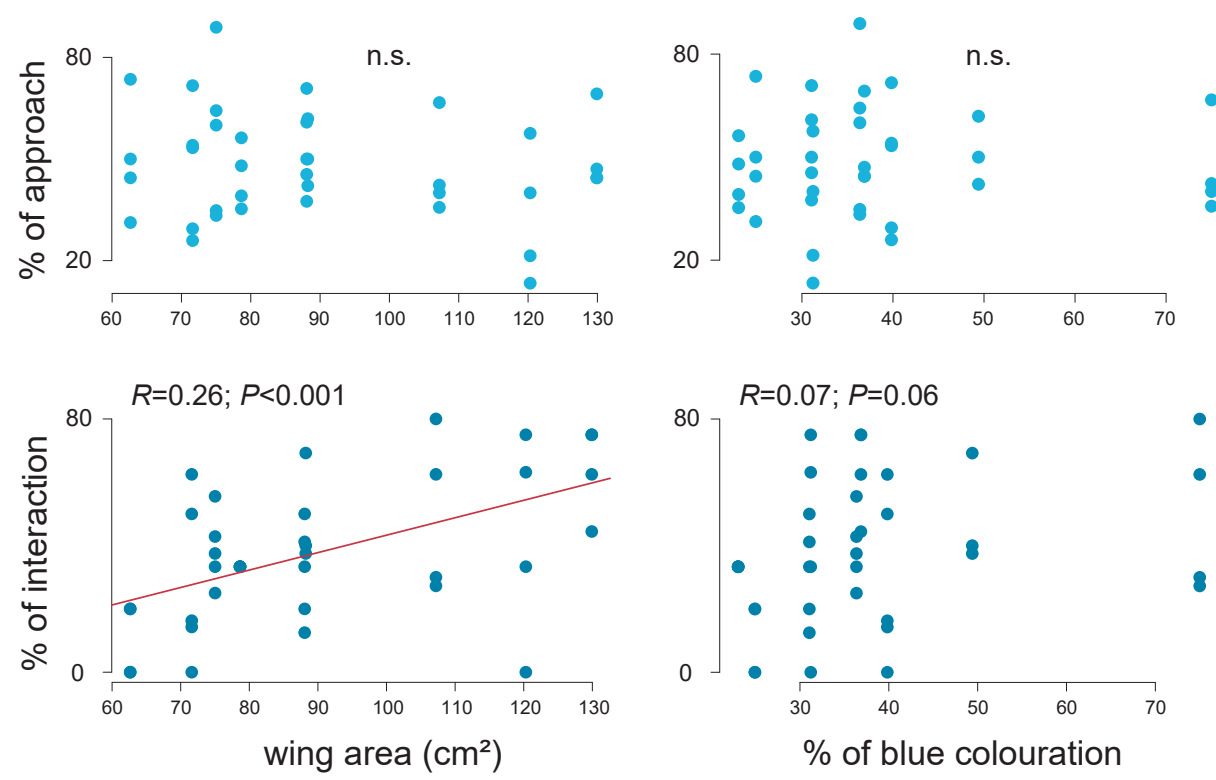

\section{Visitor M. achilles}
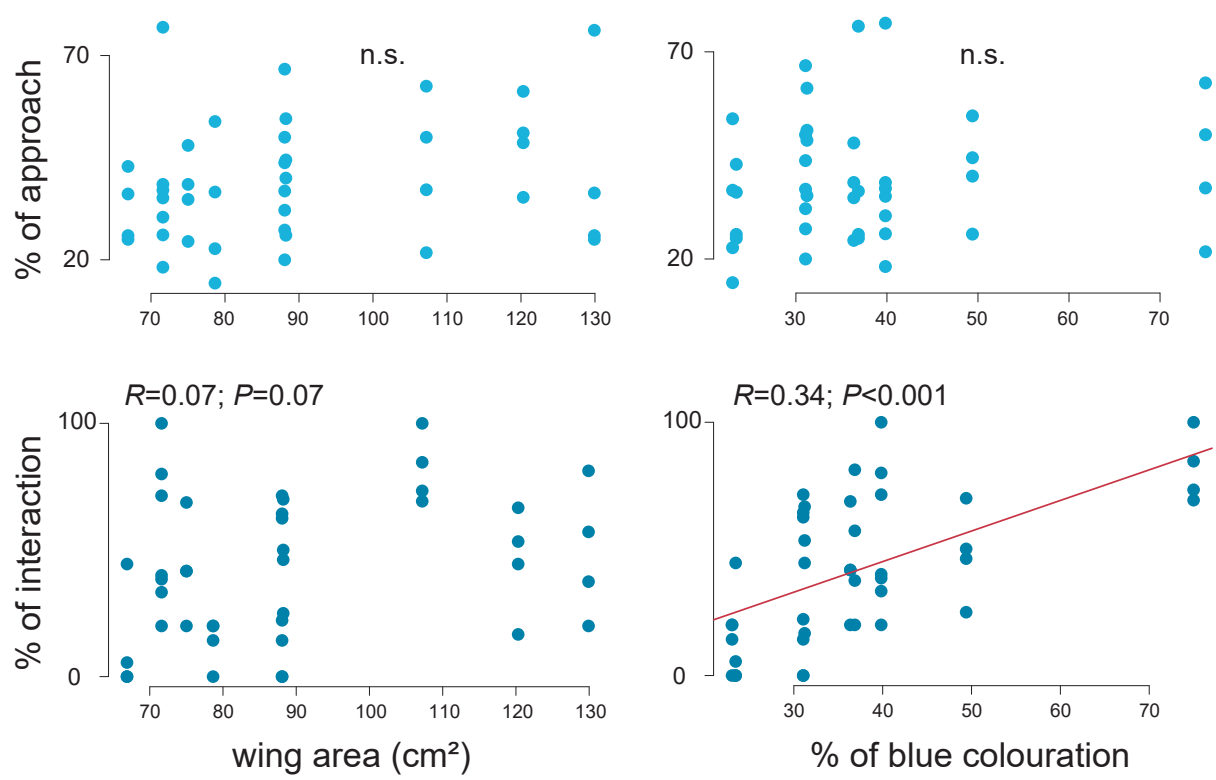

Fig. S7. The percentage of approach (top row, light blue) and the percentage of interaction (bottom row, dark blue) are showed in relation to the area and the proportion of blue colouration on the dummy wings. Top panel: visitor M. helenor. Bottom panel visitor M. achilles. Regression lines are plotted in cases of significant relationships. 
bioRxiv preprint doi: https://doi.org/10.1101/2020.1126.399931; this version posted November 27, 2020. The copyright holder for this preprint (which was not certified by peer review) is the author/funder, who has granted bioRxiv a license to display the preprint in perpetuity. It is made available under aCC-BY-NC-ND 4.0 International license.

A
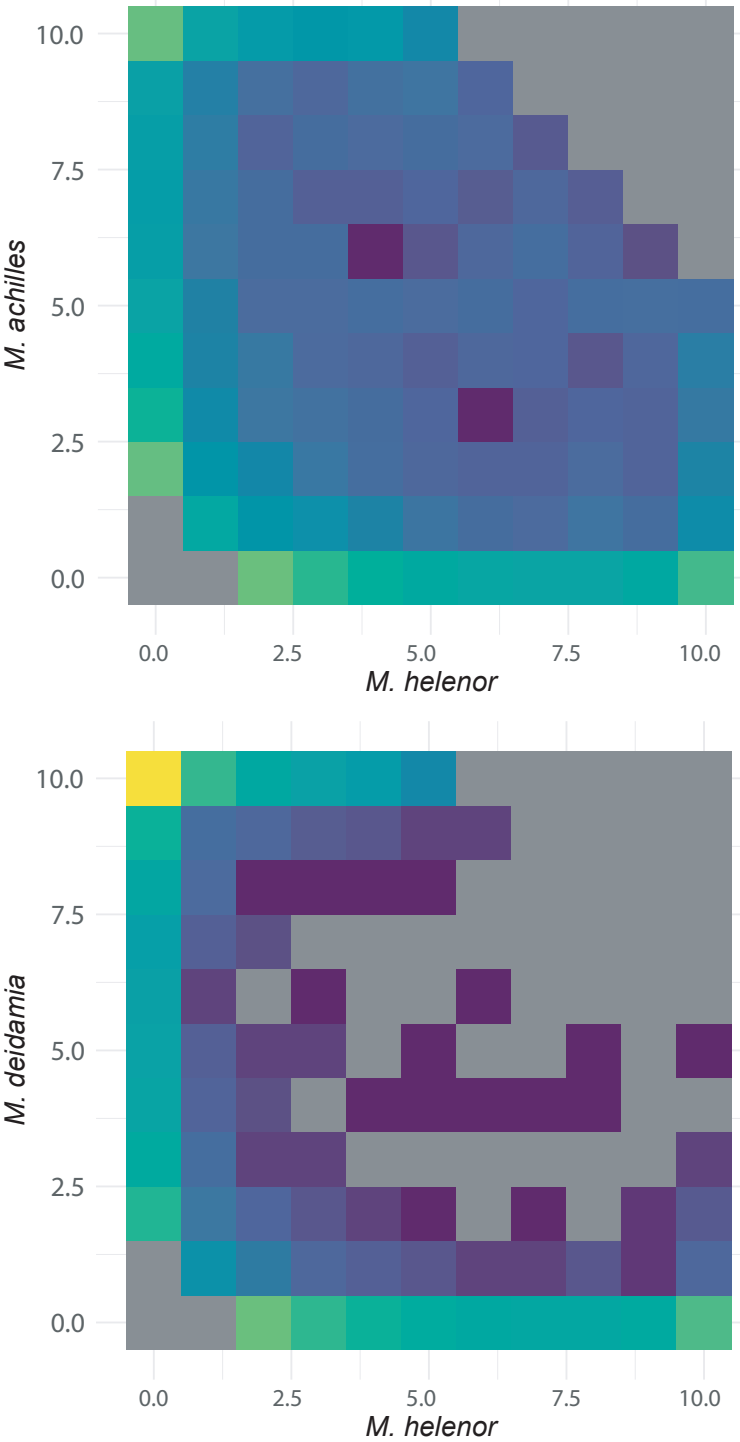

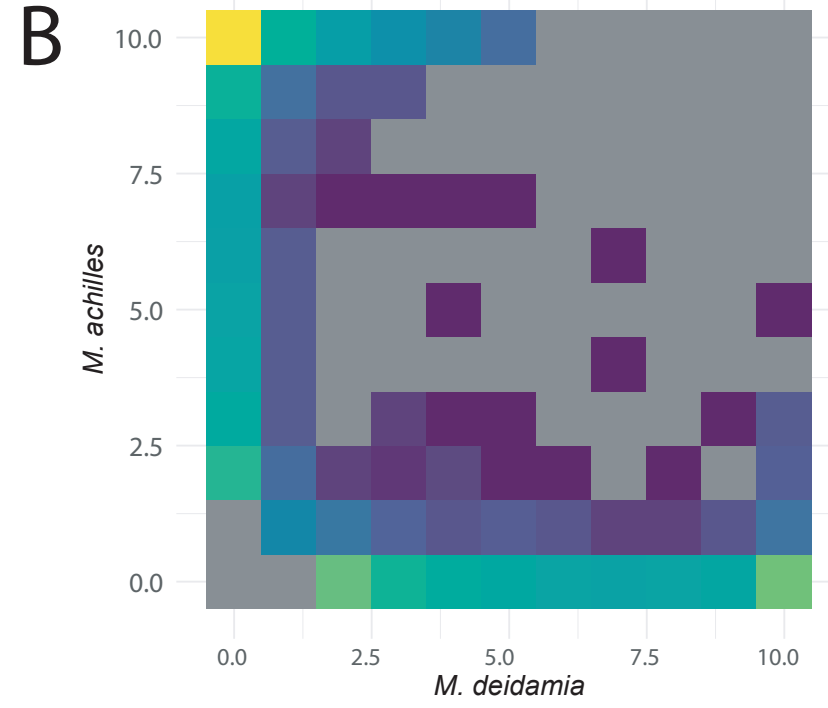

$\log 10(n S N P s)$

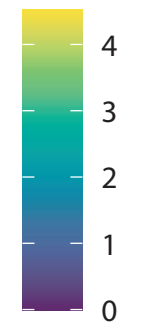

Fig. S8. Joint spectra of the allelic frequencies between M. helenor, M. achilles and M. deidamia. Folded spectrum based on the frequency of the minority allele for each polymorphic position when the three species are aligned. The intraspecific singletons have been removed from the graphical representation to avoid upscaling. Spectra are represented on the log10 scale for three different pairs A) M. helenor $-M$. achilles; B) M. deidamia - M. achilles; C) M. helenor - M. deidamia. 

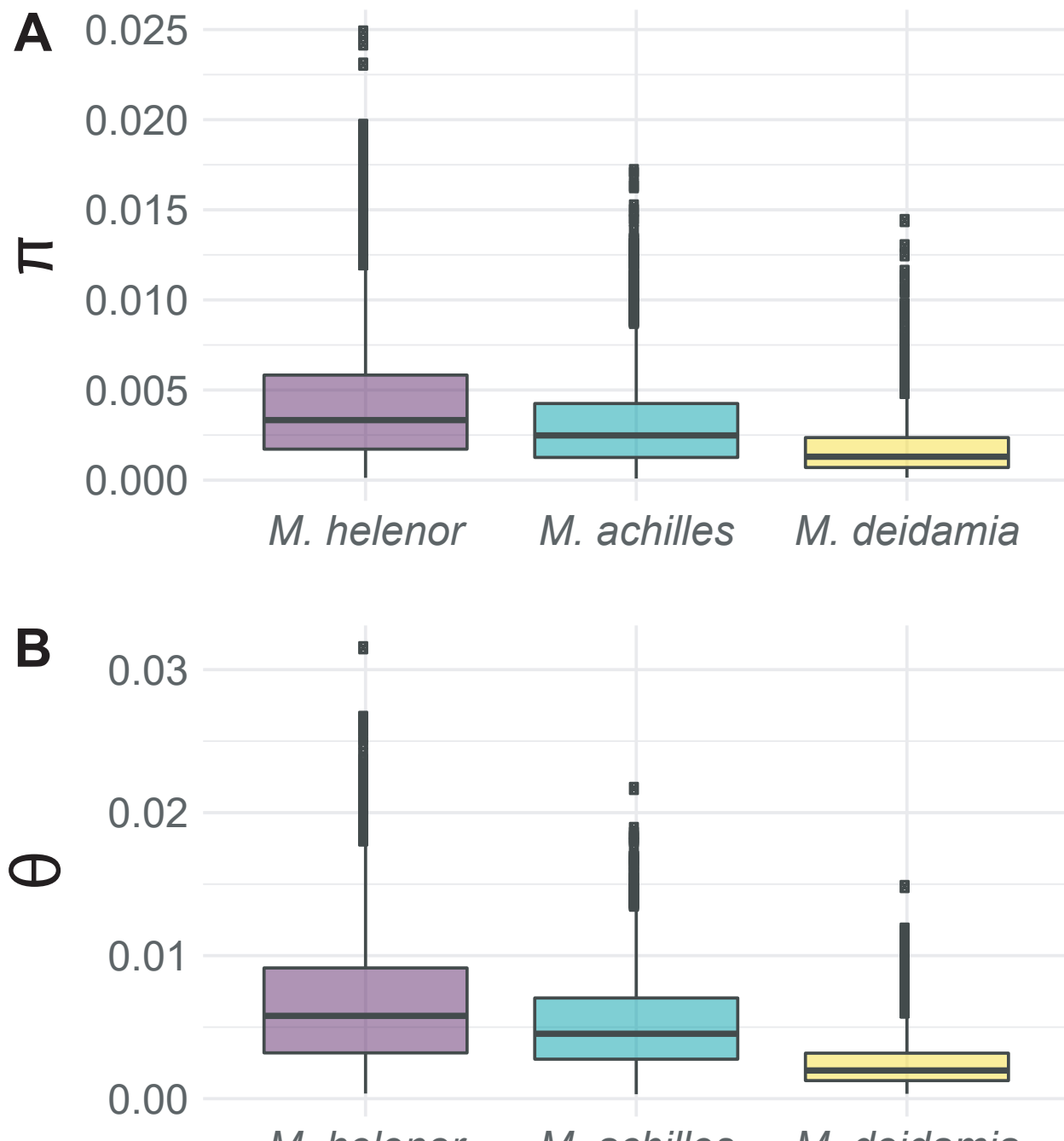
M. helenor
M. achilles
M. deidamia

C

0
$-\infty$
$-\frac{0}{0}$
$\frac{1}{\sigma}$
$=\frac{\bar{\sigma}}{\sigma}$

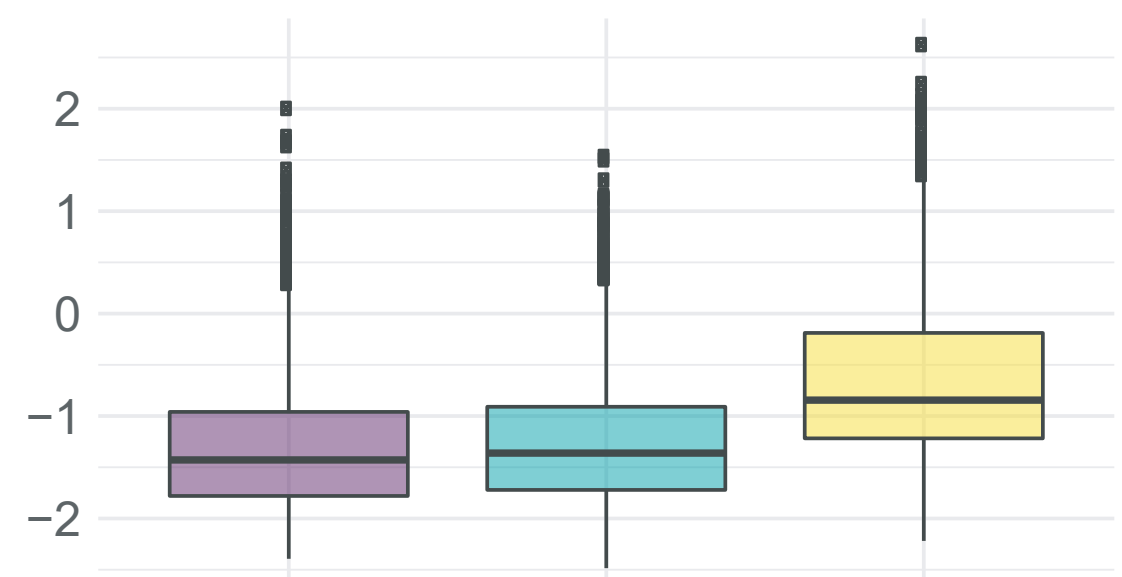

M. helenor M. achilles M. deidamia

Fig. S9. Patterns of within-species molecular diversity.

A) $\pi$ (Tajima, 1983); B) $\theta$ (Watterson, 1975); C) Taijma's D (Tajima, 1989). 
bioRxiv preprint doi: https://doi org/10.1101/2020.1126.399931; this version posted November 27, 2020. The copyright holder for this preprint (which was not certified by peer review) is the author/funder, who has granted bioRxiv a license to display the preprint in perpetuity. It is made available under aCC-BY-NC-ND 4.0 International license.

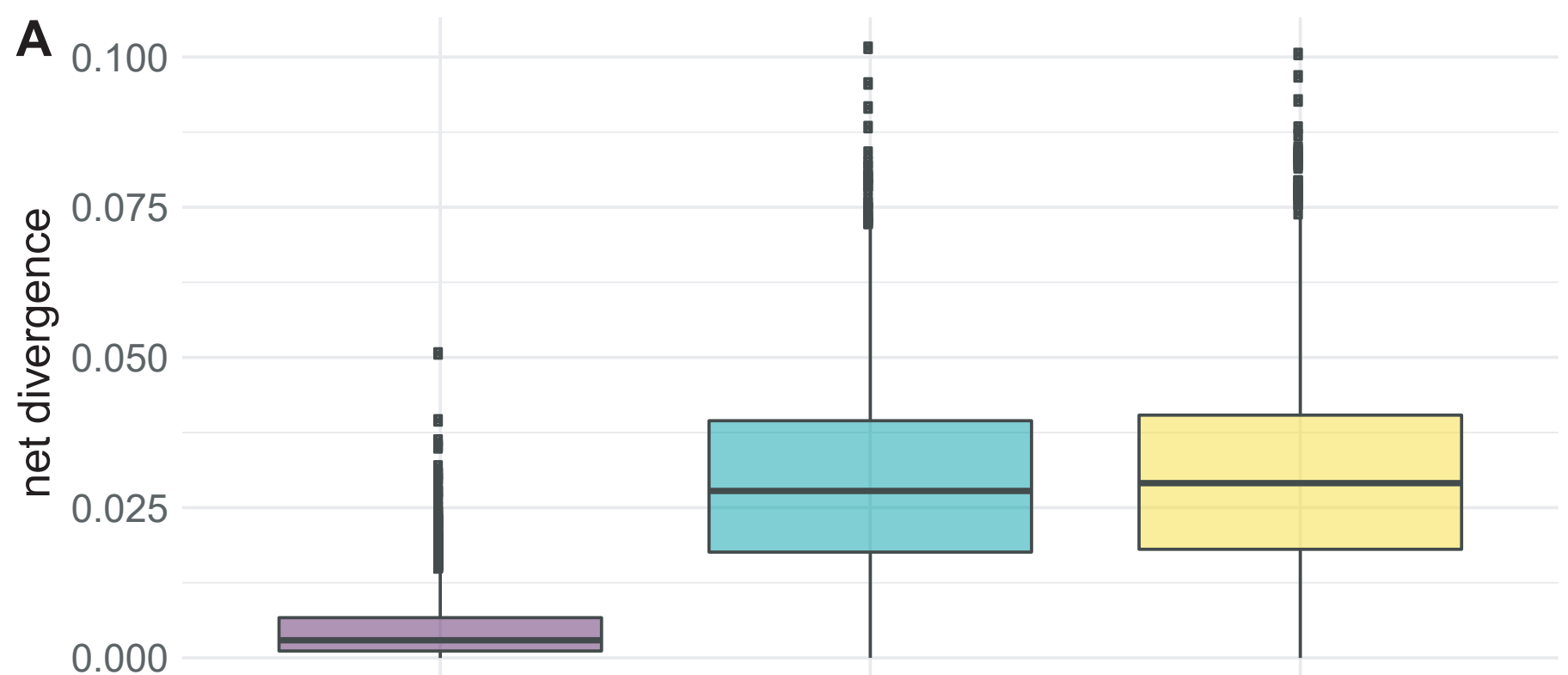
M. helenor-M. achilles
M. helenor-M. deidamia
M. achilles-M. deidamia

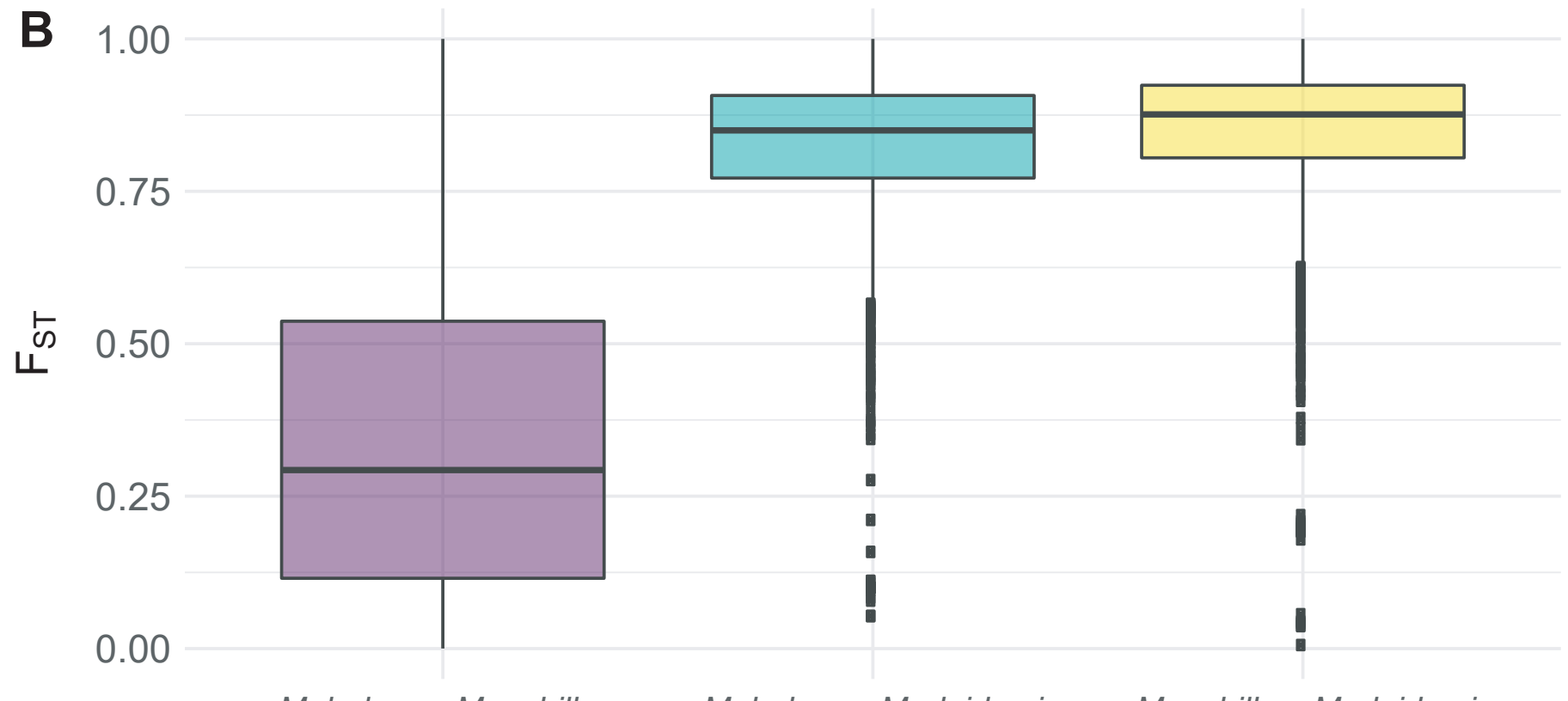
M. helenor-M. achilles
M. helenor-M. deidamia
M. achilles-M. deidamia

Fig. S10. Patterns of between-species divergence and differentiation. A) net divergence measured Da (Nei, 1987). B) Fst computed as (1 - $\pi s) / \pi T$ where $\pi s$ is the average pairwise nucleotide diversity within population and $\pi \mathrm{T}$ is the total pairwise nucleotide diversity of the pooled sample across populations. 

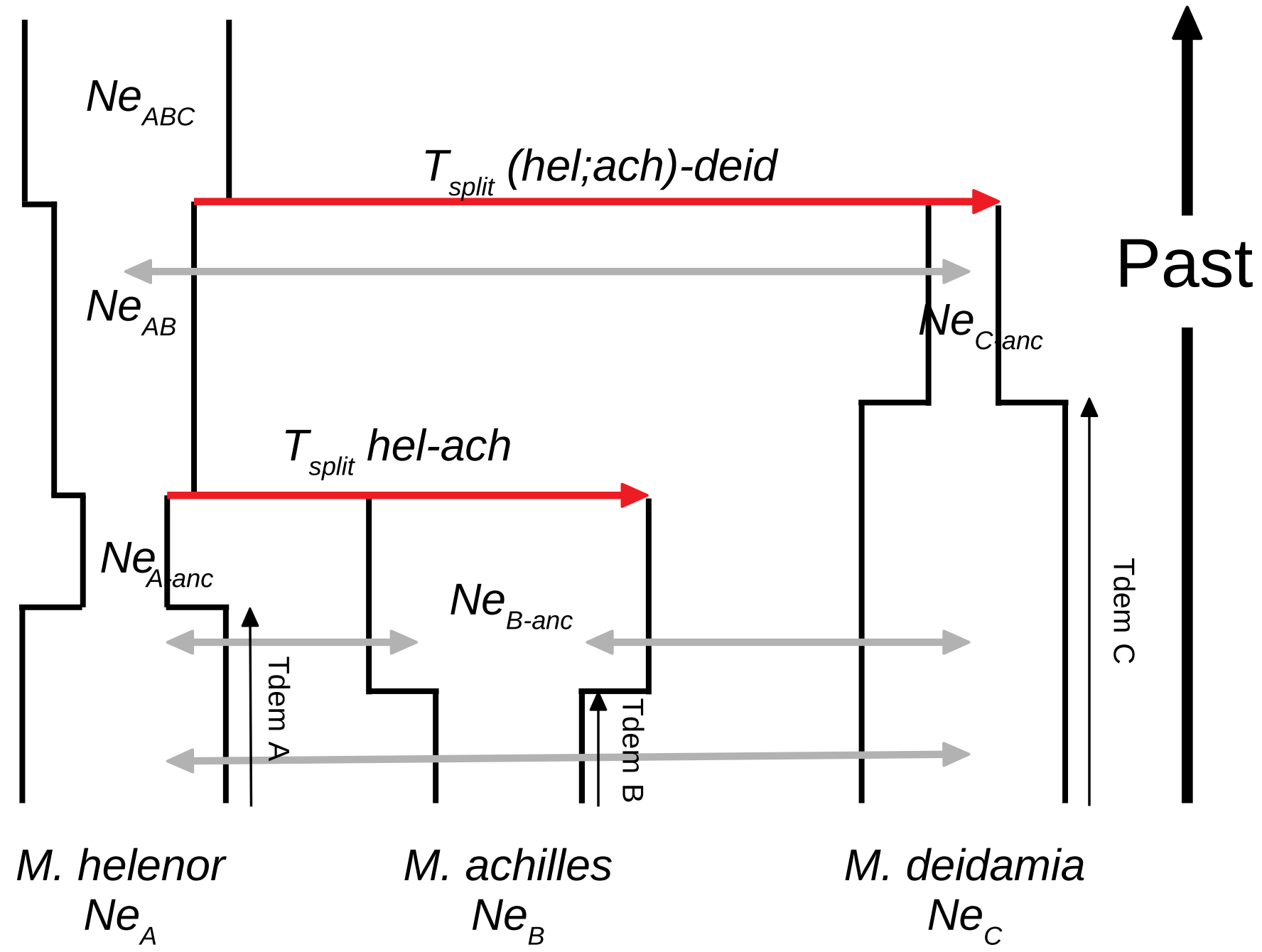

Fig. S11. General model of 3 demes speciation with gene flow. This model describes two successive splitting events from the ancestor (size $\mathrm{NeABC}$ ) to the three sampled species (sizes $\mathrm{NeA} ; \mathrm{NeB} ; \mathrm{NeC}$ ). Each split event is followed by the drawing of a new population size (after the first split: $\mathrm{NeAB}$; NeC-anc. After the second split: NeAC-anc; NeBC-anc). Populations may also undergo a demographic change in size at some point in their recent history, at times Tdem-A, Tdem-B and Tdem-C. This demographic change consists of the sampling of a new population size that may be larger or smaller than the size of their ancestor. Two migration relationships are considered: 1) migration between $C$ and (A;B). 2) migration between $A$ and $B$. Concerning the first migration relationship, 4 scenarios are explored: migration only between $A$ and $C$; only between $B$ and $C$; between $A-C$ and $B-C$; no migration at all. Concerning the second migration relationship, 2 scenarios are explored: ancient migration (restricted to the first generations after a split) and secondary contact (isolation after a split then contact with gene flow). Ages of migration changes are randomly drawn between zero and the age of the split leading to the concerned lineages. 


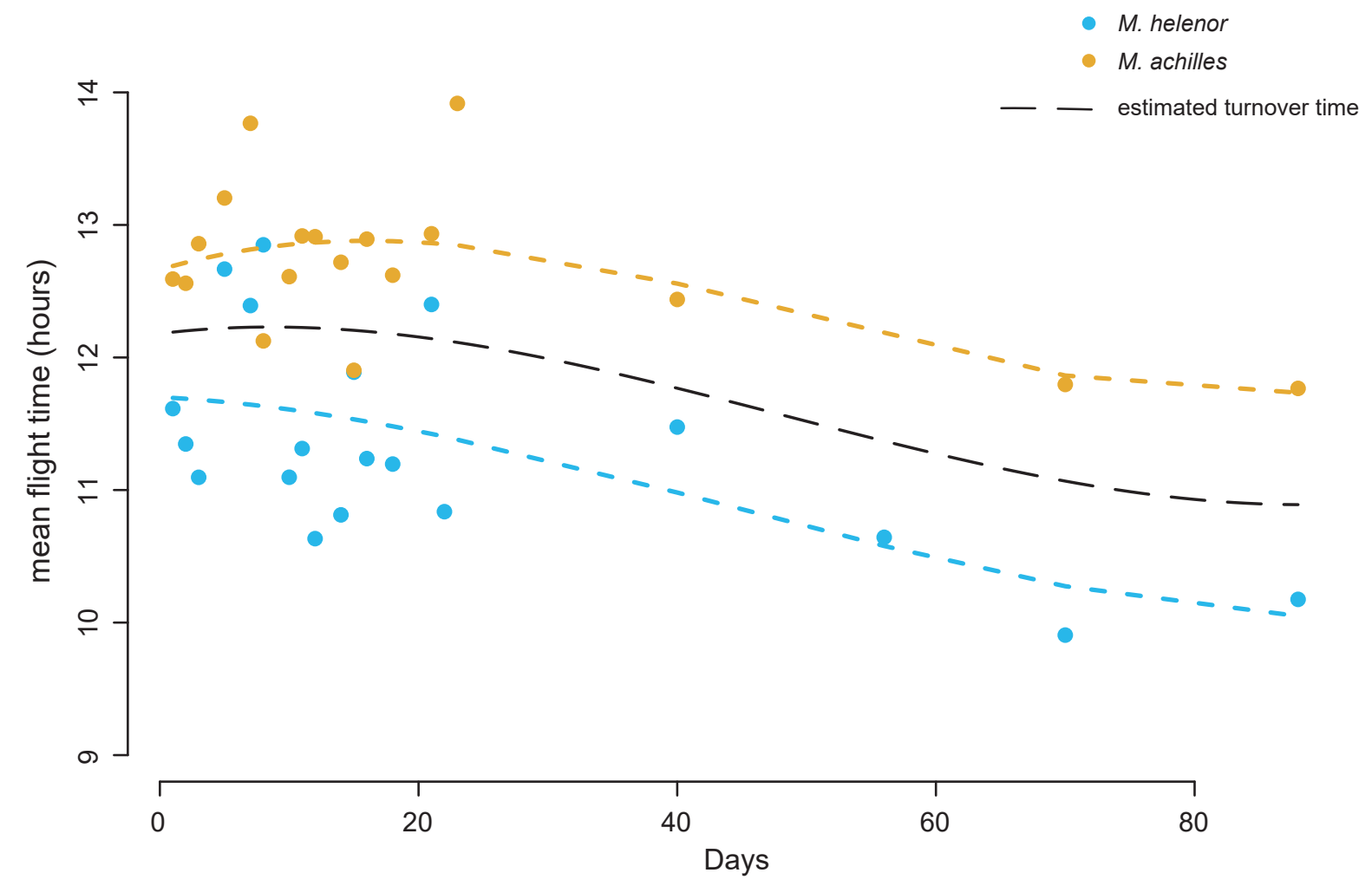

Fig. S12. Plot of the mean flight time of the two mimetic species $M$. helenor and $M$. achilles over a three-month period. Capture sessions were performed on consecutive days during the first 20 day of experiment. We then performed one day of capture every 2 weeks during 2 months in parallel to the dummy experiment to verify that temporal activity was stable over time. Because turnover time slightly change over the duration of the experiment, we estimated the identify of the flying Morpho during the dummy experiment based on the hours of the day and the turnover time estimated for this day. 
bioRxiv preprint doi: https://doi.org/10.1101/2020.11.26.399931; this version posted November 27, 2020. The copyright holder for this

preprint (which was not certified by peer review) is the author/funder, who has granted bioRxiv a license to display the preprint in perpetuity. It is made available under aCC-BY-NC-ND 4.0 International license.

Table S1. Number of captures and recaptures per Morpho species.

Total

Species
Total

number of recapture
Mean \% of recapture per day
M. helenor

M. achilles

M. deidamia
24

23.9

121

36

11
29.7

22.9 
Table S2. Effect of dummy identity (both sex confounded) on the number of approaches and interactions. The effect of dummy characteristics and of day of experiment on the number of approaches and interactions was tested using logistic regression models. Below are reported the results of likelihood ratio tests comparing models in order to test the global effect of each variable on the number of approaches and interactions.

\section{Visitor M. helenor}

\begin{tabular}{|c|c|c|c|c|c|c|c|c|c|c|c|c|c|c|c|}
\hline & \multicolumn{3}{|c|}{ Dummy identity } & \multicolumn{3}{|c|}{ Dummy sex } & \multicolumn{3}{|c|}{$\begin{array}{c}\text { Dummy wing } \\
\text { area }\end{array}$} & \multicolumn{3}{|c|}{$\begin{array}{l}\text { Dummy blue } \\
\text { proportion }\end{array}$} & \multicolumn{3}{|c|}{ Day of exp. } \\
\hline & $D$ & $d f$ & $P$ & $D$ & $d f$ & $P$ & $D$ & $d f$ & $P$ & $D$ & $d f$ & $P$ & $D$ & $d f$ & $P$ \\
\hline Approach & 12.6 & 4 & 0.01 & 0.8 & 1 & 0.35 & 0.20 & 1 & 0.65 & 0.72 & 1 & 0.39 & 58.8 & 31 & 0.00 \\
\hline Interaction & 25.6 & 4 & 0.00 & 0.6 & 1 & 0.43 & 3.3 & 1 & 0.06 & 1.0 & 1 & 0.30 & 41.6 & 31 & 0.09 \\
\hline
\end{tabular}

Visitor M. achilles

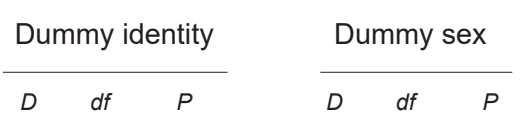

Approach

$\begin{array}{lll}11.4 & \mathbf{0 . 0 2}\end{array}$

3.5

$60.24 \quad \mathbf{0 . 0 0}$

Interaction

\begin{tabular}{lll}
\multicolumn{3}{c}{$\begin{array}{c}\text { Dummy wing } \\
\text { area }\end{array}$} \\
\hline$D \quad d f \quad P$
\end{tabular}

$\begin{array}{lll}1.7 & 1 & 0.18\end{array}$

1.11

0.28

$$
\begin{aligned}
& \begin{array}{c}
\text { Dummy blue } \\
\text { proportion }
\end{array} \\
& \hline D \quad d f \quad P
\end{aligned}
$$

$\begin{array}{lll}4.8 & 1 & \mathbf{0 . 0 2}\end{array}$

$\begin{array}{lll}6.5 & 1 & \mathbf{0 . 0 1}\end{array}$
Day of exp.

$\overline{D \quad d f \quad P}$

$\begin{array}{lll}73.6 & 36 & \mathbf{0 . 0 0}\end{array}$

$\begin{array}{lll}66.0 & 38 & \mathbf{0 . 0 0}\end{array}$ 
Table S3. Effect of dummy identity (sex separated) on the number of approaches and interactions.

The effect of dummy identity on the number of approach and interaction was tested using logistic regression models.

Below are reported the results of likelihood ratio tests comparing models in order to test the global effect of each variable on the number of approaches and interactions.

\section{Visitor M. helenor}

Male dummies

\begin{tabular}{|c|c|}
\hline Dummy identity & Day of exp. \\
\hline$d f$ & $D \quad d f$ \\
\hline
\end{tabular}

Approach

$\begin{array}{lll}4.7 & 4 & 0.31\end{array}$

$38.1 \quad 18$

0.31

Interaction

$\begin{array}{lll}12.8 & 4 & \mathbf{0 . 0 1}\end{array}$

$32.9 \quad 18$

0.01
Female dummies

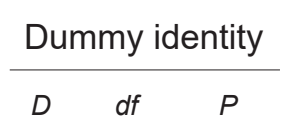

Day of exp.

D df $P$

$\begin{array}{lll}7.9 & 3 & 0.50\end{array}$

$\begin{array}{lll}19.4 & 12 & 0.07\end{array}$

$\begin{array}{lll}12.1 & 3 & \mathbf{0 . 0 0}\end{array}$

$10.6 \quad 12$

0.55

Visitor M. achilles

Male dummies

$\frac{\text { Dummy identity }}{D \quad d f \quad P}$

Approach

Interaction $\begin{array}{lll}2.7 & 4 & 0.59\end{array}$

$\begin{array}{lll}55.6 & 4 & \mathbf{0 . 0 0}\end{array}$
Day of exp.

$\bar{D} \quad d f \quad P$
Female dummies

Dummy identity

$D \quad d f \quad P$

Day of exp.

$\begin{array}{lllll}14.9 & 3 & \mathbf{0 . 0 0} & 39.9 & 14\end{array}$

0.00

$\begin{array}{lll}19.8 & 3 & \mathbf{0 . 0 0}\end{array}$

$28.6 \quad 14 \quad \mathbf{0 . 0 1}$ 
Table S4. Effect of wing area and blue proportion of the dummies on the number of approaches and interactions. The effect of dummy wing area and proportion of blue colouration on the number of approaches and interactions was tested using logistic regression models. Below are reported the results of likelihood ratio tests comparing model in order to test the global effect of each variable on the number of approaches and interactions.

\section{Visitor (all species)}

Visitor M. helenor

\begin{tabular}{|c|c|c|c|c|c|c|c|c|}
\hline \multicolumn{3}{|c|}{$\begin{array}{l}\text { Dummy wing } \\
\text { area }\end{array}$} & \multicolumn{3}{|c|}{$\begin{array}{l}\text { Dummy blue } \\
\text { proportion }\end{array}$} & \multicolumn{3}{|c|}{ Day of exp. } \\
\hline$D$ & $d f$ & $P$ & D & $d f$ & $P$ & $D$ & $d f$ & $P$ \\
\hline 2.60 & 1 & 0.10 & 0.39 & 1 & 0.52 & 132.9 & 46 & 0.00 \\
\hline 48.5 & 1 & 0.00 & 12.9 & 1 & 0.00 & 117.1 & 46 & 0.00 \\
\hline
\end{tabular}

Visitor M. achilles

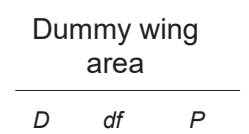

Dummy blue

proportion
$D \quad d f \quad P$

Day of exp.

Approach

$\begin{array}{lll}1.7 & 1 & 0.18\end{array}$

$0.98 \quad 1$

0.33

$\begin{array}{lll}70.5 & 36 & \mathbf{0 . 0 0}\end{array}$

Interaction

$22.1 \quad 1 \quad \mathbf{0 . 0 0}$

0.121

0.72

47.136

0.10

\section{Dummy blue} proportion

$\bar{D} \quad d f \quad P$

$\begin{array}{lll}0.0 & 1 & 0.82\end{array}$

$30.1 \quad 1 \quad \mathbf{0 . 0 0}$
Day of exp.

$\bar{D} \quad d f \quad P$

$83.1 \quad 40 \quad \mathbf{0 . 0 0}$

$83.9 \quad 40 \quad \mathbf{0 . 0 0}$

Interaction 
Table S5. Parameters inferred by Random Forest for the best fitting model (Fig. 4 ; (Raynal et al., 2019)).

\begin{tabular}{lrrr}
\hline Parameters & Estimated value & Quantile $\mathbf{2 . 5} \%$ & Quantile $\mathbf{9 7 . 5} \%$ \\
\hline Effective population sizes (Ne) in number of diploid individuals & & \\
\hline Ne M. helenor (current) & 645,401 & 449,793 & 698,620 \\
Ne M. helenor (bottleneck) & 300,790 & 17,905 & 669,893 \\
Ne M. achilles (current) & 631,518 & 433,301 & 698,481 \\
Ne M. achilles (bottleneck) & 187,174 & 12,588 & 637,813 \\
Ne M. deidamia (current) & 496,636 & 237,820 & 690,466 \\
Ne M. deidamia (bottleneck) & 113,487 & 8,589 & 505,687 \\
Ne M. helenor - M. achilles (ancestor) & 409,703 & 87,599 & 673,563 \\
Ancestral Ne & 649,647 & 520,520 & 698,332 \\
Shape parameter alpha & 4.55 & 0.81 & 9.96 \\
Shape parameter beta & 10.20 & 0.57 & 19.59 \\
\hline
\end{tabular}

Time of demographic events in number of generations

\begin{tabular}{lrrr}
\hline M. helenor expansion & 677,138 & 30,165 & $1,711,892$ \\
M. achilles expansion & 545,804 & 26,027 & $1,559,309$ \\
M. deidamia expansion & 455,822 & 16,735 & $1,695,739$ \\
Split M. helenor - M. achilles & $1,110,618$ & 356,427 & $3,451,551$ \\
Ancestral split & $4,133,448$ & $3,860,151$ & $4,562,831$ \\
Arrest of migration M. helenor - M. achilles & 769,233 & 346,007 & $1,270,989$ \\
\hline
\end{tabular}

\begin{tabular}{lrrr}
\hline Migration (4.N.m" & & & \\
\hline M. achilles $\rightarrow$ M. helenor & & & \\
\hline Migration rate & 25.27 & 2.86 & 48.93 \\
Shape parameter alpha & 9.81 & 0.37 & 19.67 \\
Shape parameter beta & 10.22 & 0.36 & 19.68 \\
\hline $\boldsymbol{M}$ helenor $\rightarrow$ M. achilles & & & \\
\hline Migration rate & 25.36 & 2.83 & 49.22 \\
Shape parameter alpha & 10.37 & 0.33 & 19.62 \\
Shape parameter beta & 9.82 & 0.37 & 19.66 \\
\hline
\end{tabular}

